\title{
Combination simvastatin and metformin induces G1-phase cell cycle arrest and Ripk1- and Ripk3- dependent necrosis in C4-2B osseous metastatic castration-resistant prostate cancer cells
}

\author{
MA Babcook ${ }^{1,2}$, RM Sramkoski $^{3}$, H Fujioka ${ }^{4,5}$, F Daneshgari ${ }^{2}$, A Almasan $^{6,7}$, S Shukla ${ }^{2}$, RR Nanavaty $^{8}$ and S Gupta*,1,2,9
}

Castration-resistant prostate cancer (CRPC) cells acquire resistance to chemotherapy and apoptosis, in part, due to enhanced aerobic glycolysis and biomass production, known as the Warburg effect. We previously demonstrated that combination simvastatin (SIM) and metformin (MET) ameliorates critical Warburg effect-related metabolic aberrations of C4-2B cells, synergistically and significantly decreases CRPC cell viability and metastatic properties, with minimal effect on normal prostate epithelial cells, and inhibits primary prostate tumor growth, metastasis, and biochemical failure in an orthotopic model of metastatic CRPC, more effectively than docetaxel chemotherapy. Several modes of cell death activated by individual treatment of SIM or MET have been reported; however, the cell death process induced by combination SIM and MET treatment in metastatic CRPC cells remains unknown. This must be determined prior to advancing combination SIM and MET to clinical trial for metastatic CRPC. Treatment of C4-2B cells with combination $4 \mu \mathrm{M}$ SIM and $2 \mathrm{mM}$ MET (SIM+MET) led to significant G1-phase cell cycle arrest and decrease in the percentage of DNA-replicating cells in the S-phase by $24 \mathrm{~h}$; arrest was sustained throughout the 96-h treatment. SIM+MET treatment led to enhanced autophagic flux in C4-2B cells by 72-96 $\mathrm{h}$, ascertained by increased LC3B-II (further enhanced with lysosomal inhibitor chloroquine) and reduced Sequestosome-1 protein expression, significantly increased percentage of acidic vesicular organelle-positive cells, and increased autophagic structure accumulation assessed by transmission electron microscopy. Chloroquine, however, could not rescue CRPC cell viability, eliminating autophagic cell death; rather, autophagy was upregulated by C4-2B cells in attempt to withstand chemotherapy. Instead, SIM+MET treatment led to Ripk1- and Ripk3-dependent necrosis by 48-96 h, determined by propidium iodide-Annexin V flow cytometry, increase in Ripk1 and Ripk3 protein expression, necrosome formation, HMGB-1 extracellular release, and necrotic induction and viability rescue with necrostatin-1 and Ripk3-targeting siRNA. The necrosis-inducing capacity of SIM+MET may make these drugs a highly-effective treatment for apoptosis- and chemotherapy-resistant metastatic CRPC cells.

Cell Death and Disease (2014) 5, e1536; doi:10.1038/cddis.2014.500; published online 20 November 2014

In the United States, 30000 men die each year from metastasis- and treatment-related complications of metastatic castration-resistant prostate cancer (CRPC). ${ }^{1}$ Depending on symptoms and prognosis, a variety of chemotherapies, immunotherapies, and radiotherapies are available; ${ }^{2}$ these treatment modalities modestly improve median progression-free and overall survival, but often with a toll on quality-of-life.,3 Another major issue is development of chemotherapeutic resistance., ${ }^{3,4}$ More effective alternative therapies for metastatic CRPC are being sought.

One method of chemotherapeutic development involves taking advantage of aberrant cancer metabolism to target cancer cells while leaving normal cells unharmed. Aberrant cancer metabolism involves constitutive activity of the PI3K/ Akt signaling pathway, inhibited adenosine monophosphateactivated protein kinase (AMPK) activity, and rampant aerobic

\footnotetext{
${ }^{1}$ Department of Nutrition, Case Western Reserve University School of Medicine, Cleveland, OH 44106, USA; ${ }^{2}$ Department of Urology, Case Western Reserve University School of Medicine \& The Urology Institute, University Hospitals Case Medical Center, Cleveland, OH 44106, USA; ${ }^{3}$ Cytometry \& Imaging Microscopy Core Facility, Case Comprehensive Cancer Center, Cleveland, OH 44106, USA; ${ }^{4}$ Electron Microscopy Core Facility and Center for Mitochondrial Disease, Case Western Reserve University School of Medicine, Cleveland, OH 44106, USA; ${ }^{5}$ Department of Pharmacology, Case Western Reserve University School of Medicine, Cleveland, OH 44106, USA; ${ }^{6}$ Department of Cancer Biology, Lerner Research Institute, Cleveland Clinic, Cleveland, OH 44195, USA; ${ }^{7}$ Department of Radiation Oncology, Taussig Cancer Institute, Cleveland Clinic, Cleveland, OH 44195, USA; ${ }^{8}$ Department of Biomedical Science, The Ohio State University, Columbus, OH 43210, USA and ${ }^{9}$ Division of General Medical Sciences, Case Comprehensive Cancer Center, Cleveland, OH 44106, USA

${ }^{*}$ Corresponding author: S Gupta, Department of Urology, Case Western Reserve University School of Medicine \& The Urology Institute, University Hospitals Case Medical Center, 10900 Euclid Avenue, Cleveland, OH 44106, USA. Tel: +216 368 6162; Fax: +216 368 0213; E-mail: sanjay.gupta@ case.edu

Abbreviations: AMPK, adenosine monophosphate-activated protein kinase; AO, acridine orange; AV, Annexin V; AVOs, acidic vesicular organelles; $C Q$, chloroquine; CRPC, castration-resistant prostate cancer; GAPDH, glyceraldehyde-3-phosphate dehydrogenase; LC3, microtubule-associated protein 1 light chain 3; MET, metformin; Nec-1, necrostatin-1; PARP, poly (ADP-ribose) polymerase; PE, phosphatidylethanolamine; PI, propidium iodide; Ripk1 and Ripk3, receptor-interacting protein kinase 1 and 3; SIM, simvastatin; SQSTM1, sequestosome 1; TEM, transmission electron microscopy; TRADD, tumor necrosis factor receptor-associated death domain

Received 02.9.14; accepted 13.10.14; Edited by A Stephanou
} 
glycolysis and glutamine utilization to significantly increase biomass synthesis necessary for accelerated cell growth, proliferation, and metastasis, known as the 'Warburg effect'. .,6 These metabolic alterations, including high p-Ser-473 Akt immunohistochemical staining and significantly elevated protein, fatty acid, and cholesterol concentrations (suggesting inhibited AMPK activity and increased macromolecule synthesis) were noted in primary prostate tumors of patients who progressed to biochemical failure or metastasis and in osseous metastases of prostate cancer. ${ }^{7-9}$ We also demonstrated constitutive activation of Akt, reduced AMPK activity, and significantly increased cholesterol synthesis in C4-2B in vitro models of metastatic CRPC. ${ }^{10}$

Exploiting metabolic aberrations present in CRPC cells for novel preclinical chemotherapeutic development, we devised a combination chemotherapy utilizing simvastatin (SIM) and metformin (MET). ${ }^{10}$ SIM is a potent inhibitor of 3-hydroxy-3methylglutaryl-CoA reductase, the first rate-limiting enzyme of the mevalonate pathway, ${ }^{11}$ and MET is an indirect activator of AMPK, which acts by inhibiting the mitochondrial complex I and lowering the cellular ATP-to-AMP ratio. ${ }^{12}$ We previously demonstrated that 1:500 combination SIM+MET within pharmacological range significantly reduces Akt phosphorylation and increases AMPK activity, causing inhibition of downstream anabolic pathways, in $\mathrm{C} 4-2 \mathrm{~B}$ osseous metastatic CRPC cells. ${ }^{10}$ SIM+MET also synergistically inhibited CRPC cell viability and significantly abated metastatic properties in vitro, with minimal adverse effect on normal prostate epithelial cell viability, and significantly inhibited prostate primary tumor growth and prevented metastasis in an orthotopic model of metastatic CRPC. ${ }^{10}$ Suppression of Akt activity and reactivation of AMPK restrains aerobic glycolysis and macromolecule synthesis in cancer cells, inhibits proliferation and metastatic capability, and results in cell death. ${ }^{5,10}$

SIM+MET treatment reduces C4-2B cell viability $>90 \%$ by $96 \mathrm{~h}^{10} \mathrm{SIM}$ treatment was shown to induce cancer cell death by apoptosis, necrosis, or autophagy, ${ }^{13-15}$ and MET treatment leads to apoptosis or autophagy in prostate and other cancers. ${ }^{16-17}$ The mode of cell death activated by combination SIM+MET in metastatic CRPC cells has not been elucidated, but is important to define prior to pursuing potential clinical
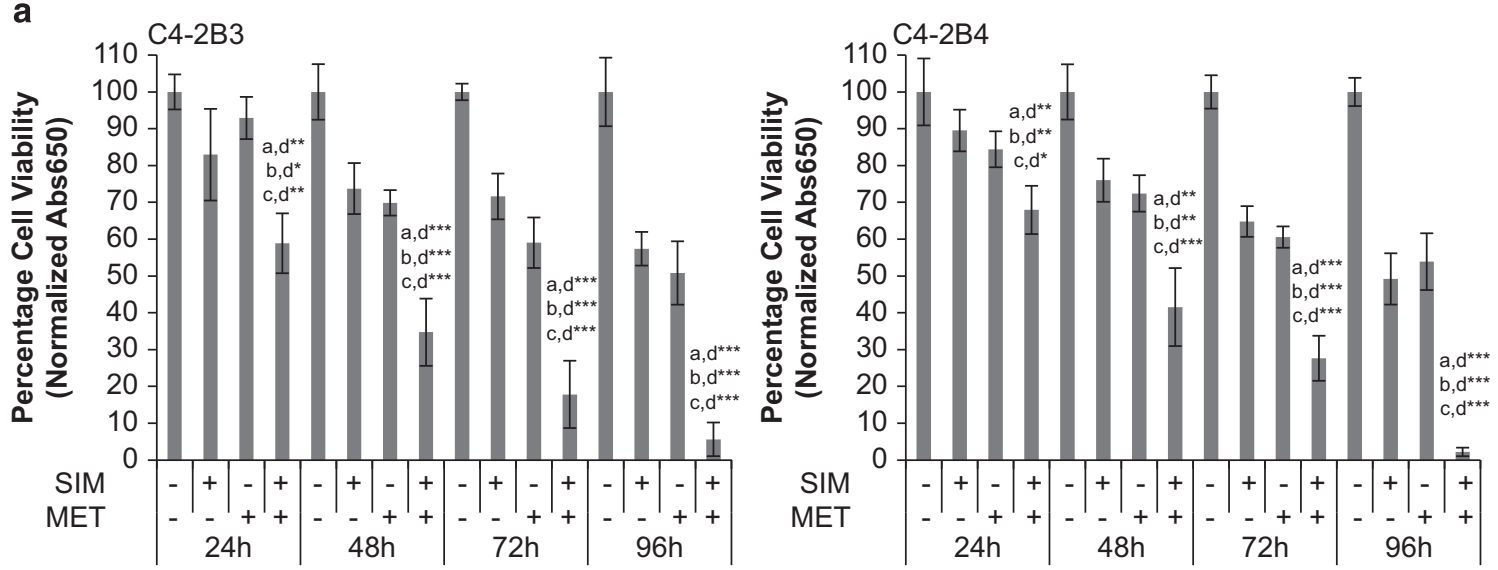

b
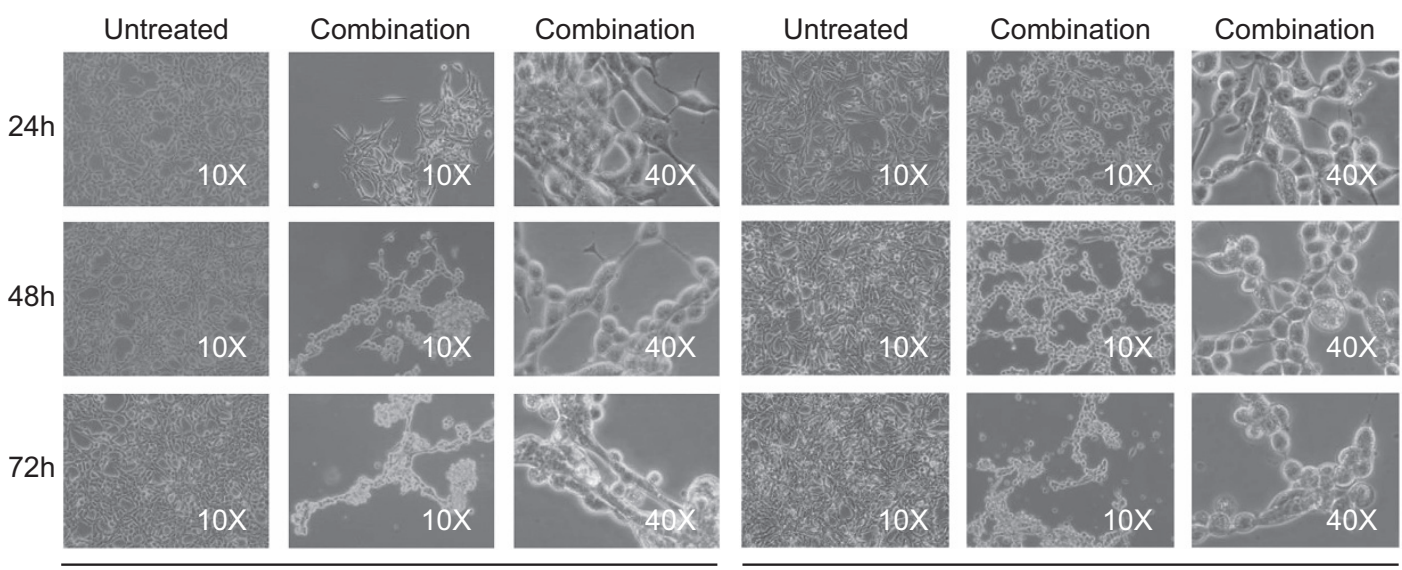

C4-2B3

C4-2B4

Figure 1 Combination simvastatin and metformin treatment significantly inhibits C4-2B metastatic CRPC cell viability. (a) Percentage cell viability (mean \pm S.D.) by the methylene blue assay in C4-2B3 and C4-2B4 cells following treatment with $4 \mu \mathrm{M}$ simvastatin (SIM) and/or $2 \mathrm{mM}$ metformin (MET) for $24-96 \mathrm{~h}, n=3$ per treatment group ${ }^{\star} P<0.05,{ }^{* *} P<0.01,{ }^{* *} P<0.001$ determined by ANOVA followed by the Tukey multiple comparison procedure where $a=$ untreated, $b=S I M, c=M E T$, and $d=S I M+M E T$ in comparisons. (b) Light microscope images at $\times 10$ and $\times 40$ magnification of untreated and combination $4 \mu \mathrm{M} \mathrm{SIM}$ and $2 \mathrm{mM}$ MET-treated C4-2B3 and C4-2B4 cells at $24-72 \mathrm{~h}$ ( $96 \mathrm{~h}$ not shown as only $2-6 \%$ of SIM+MET-treated C4-2B cells remain viable at that time point) 
application. Therefore, the purpose of this study was to determine the cell death process induced in C4-2B cells by SIM+MET treatment.

\section{Results}

SIM+MET treatment induces G1-phase cell cycle arrest in CRPC cells. SIM+MET treatment significantly inhibits C42B3/B4 cell viability, with $94-98 \%$ of cells nonviable by $96 \mathrm{~h}$ (Figures $1 \mathrm{a}$ and $\mathrm{b}$ ). We previously demonstrated that SIM +MET significantly decreases Akt phosphorylation and activation and significantly increases AMPKa activity, starving C4-2B cells of macromolecules required for growth, proliferation, metastasis, and survival. ${ }^{10,18}$ Inhibition of the glycolytic pathway and biomass synthesis often leads to cell cycle arrest. ${ }^{19}$ Individually, statins and MET induce cell cycle arrest in prostate cancer cells. ${ }^{16-17,20}$ Therefore, we first investigated whether SIM+MET treatment causes cell cycle arrest in
C4-2B cells by propidium iodide (PI) DNA staining and flow cytometric analysis. Compared with untreated and SIM or MET individually treated C4-2B cells, SIM+MET treatment led to significant G1-phase arrest and decrease in percentage of DNA-replicating cells in the S-phase by $24 \mathrm{~h}$ treatment, and arrest was sustained throughout the 96-h treatment (Figure 2). Therefore, SIM+MET teatment led to an earlier, more pronounced, sustained, and significant G1-phase cell cycle arrest compared with SIM or MET treatment alone; this is sensible, as nutrient restriction generally leads to arrest at the G1-phase checkpoint.

SIM+MET treatment does not induce apoptosis in CRPC cells. Sustained cell cycle arrest leads to cell death. Apoptosis is the dominant cell death process induced by SIM in prostate cancer cells; ${ }^{13,21}$ MET also causes cell death by apoptosis in prostate cancer cells. ${ }^{16}$ With no prior reports regarding mechanism of cell death of combination SIM+MET
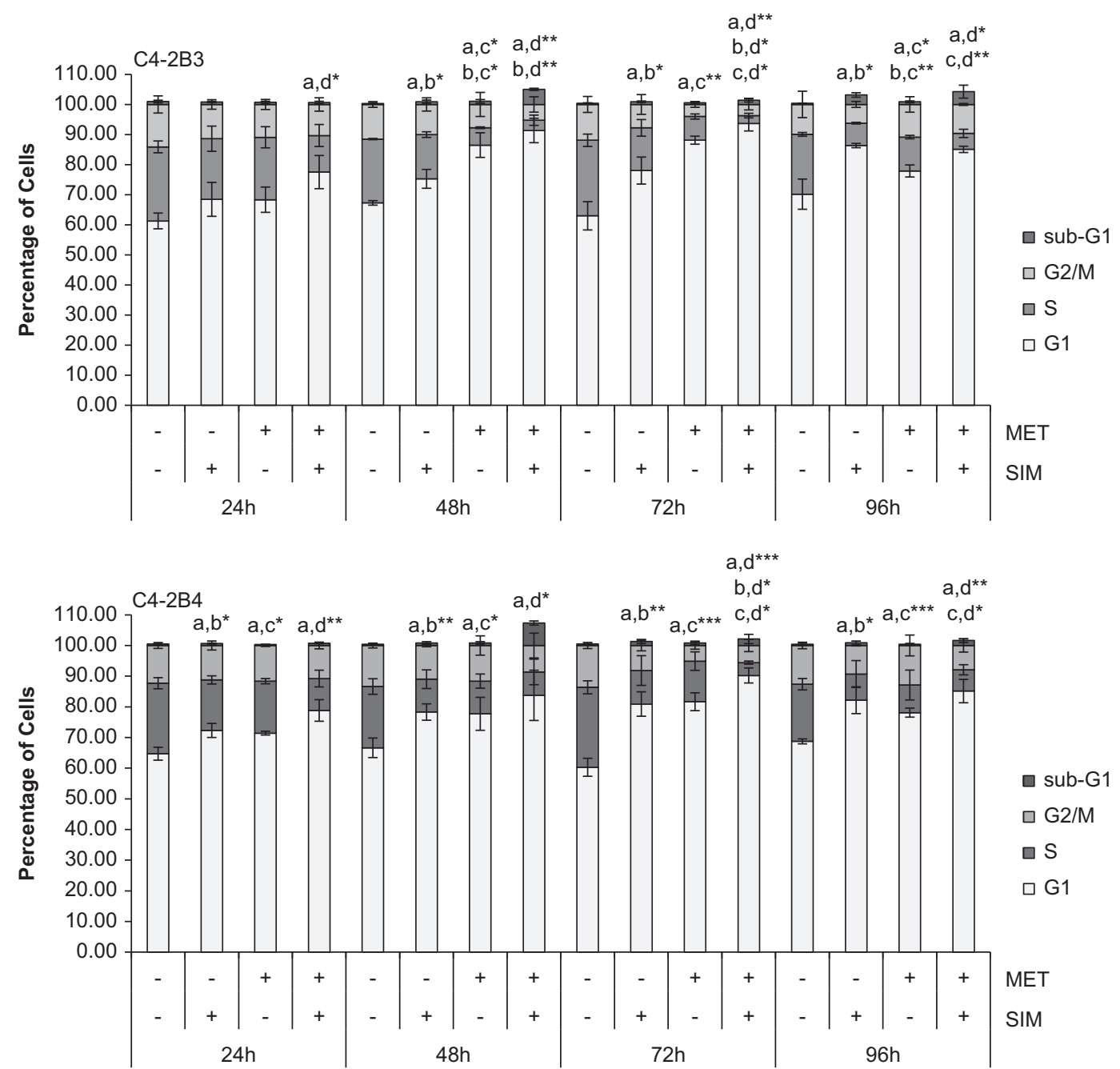

Figure 2 Combination simvastatin and metformin treatment induces significant, sustained G1-phase cell cycle arrest in C4-2B metastatic CRPC cells. C4-2B3 and C4-2B4 cells were treated with $4 \mu \mathrm{M}$ simvastatin (SIM) and $2 \mathrm{mM}$ metformin (MET) for $24-96 \mathrm{~h}$ followed by staining with propidium iodide and analysis by flow cytometry. Percentage of cells (mean \pm S.D.) in G1, S, and G2/M phases of the cell cycle and sub-G1 represented in bar graphs, $n=3$ per treatment group. Significance of G1-phase cell cycle arrest, where ${ }^{*} P<0.05,{ }^{* *} P<0.01,{ }^{* *} P<0.001$, determined by ANOVA followed by the Tukey multiple comparison procedure where $a=$ untreated, $b=S$ IM, $c=$ MET, and $\mathrm{d}=\mathrm{SIM}+\mathrm{MET}$ in comparisons 
in any cancer cell, we first investigated whether cell death is through apoptosis.

Apoptosis may be caused by toxins or nutrient deprivation and is characterized by cellular blebbing, cytoplasmic and nuclear shrinkage, chromatin condensation, and DNA fragmentation. ${ }^{22,23}$ The spike $(5.0-7.3 \%)$ of sub-G1 cells noted at 48-h SIM+MET treatment (Figure 2), indicative of DNA fragmentation, suggests some C4-2B cells may be a

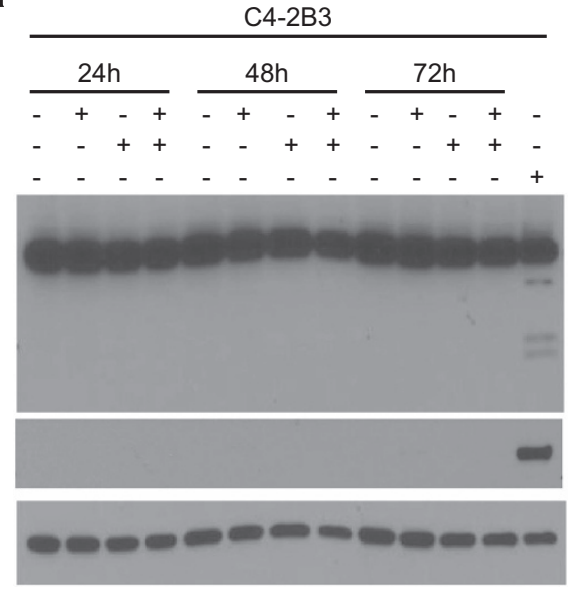

b

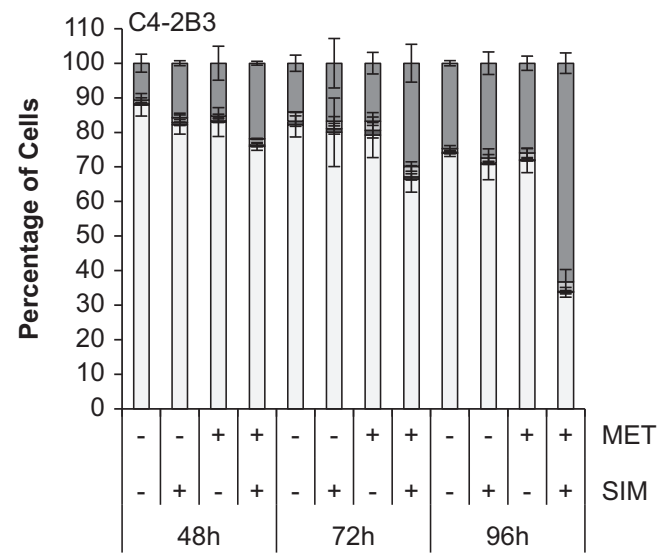

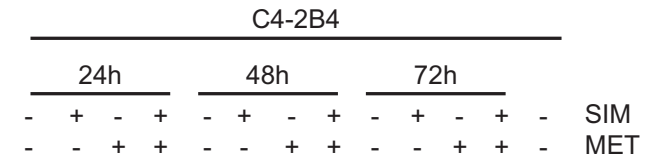

$-\quad++-{ }_{-}++-{ }_{-}++-$MET

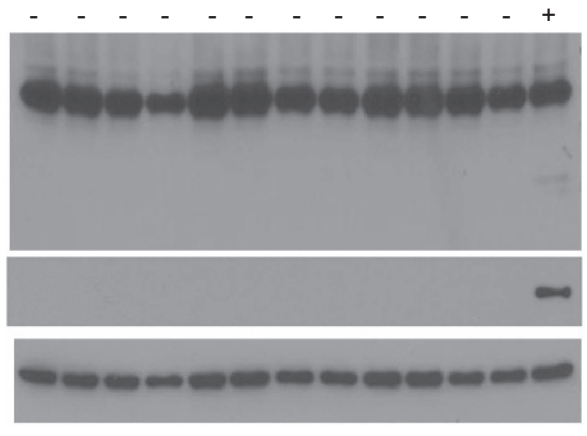

$35 \mathrm{kDa}$,

Full-length Caspase-3

$17,19 \mathrm{kDa}$,

Cleaved Caspase-3

$89 \mathrm{kDa}$

Cleaved PARP

$37 \mathrm{kDa}$, GAPDH

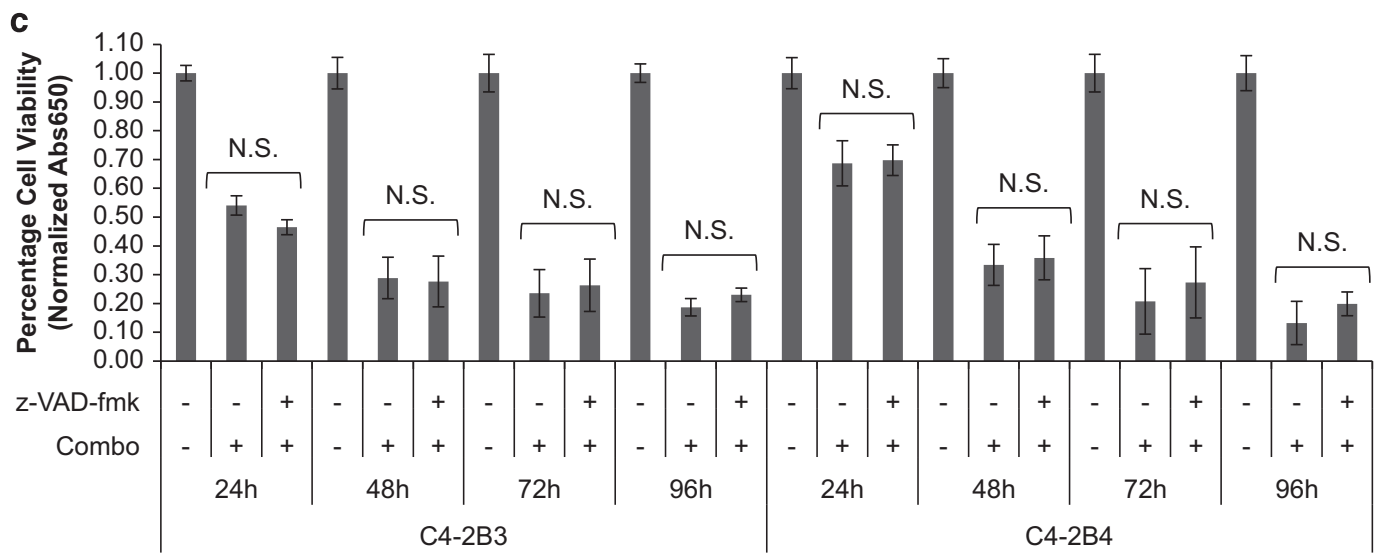

Figure 3 Combination simvastatin and metformin treatment does not induce apoptosis in C4-2B metastatic CRPC cells. (a) Western blot analysis of total and cleaved caspase-3 and cleaved PARP protein expression from total cell lysates of C4-2B3 and C4-2B4 cells following treatment with $4 \mu \mathrm{M}$ simvastatin (SIM) and/or $2 \mathrm{mM} \mathrm{metformin} \mathrm{(MET)}$ for $24-72 \mathrm{~h}$. Total cell lysates of C4-2B3 and C4-2B4 cells treated with $2 \mu \mathrm{M}(\mathrm{S})-(+)$-camptothecin (CAMP) for $48 \mathrm{~h}$ used as apoptosis positive control. GAPDH used as loading control. (b) C4-2B3 and C4-2B4 cells treated with $4 \mu \mathrm{M}$ SIM and/or $2 \mathrm{mM} \mathrm{MET} \mathrm{for} 48-96 \mathrm{~h}$ followed by staining with FITC-conjugated Annexin V (AV) and propidium iodide (PI) and analyzed by flow cytometry. Percentage of $\mathrm{PI}(-) \mathrm{AV}(-), \mathrm{PI}(-) \mathrm{AV}(+), \mathrm{PI}(+) \mathrm{AV}(-)$, and $\mathrm{PI}(+) \mathrm{AV}(+)$ cells demonstrated in bar graphs of mean $\pm \mathrm{S}$. D. from triplicate samples. Representative density plots of controls and samples shown in Supplementary Figure S1. (c) Percentage cell viability (mean \pm S.D.) by methylene blue assay of C4-2B3 and C4-2B4 cells following treatment with combination $4 \mu \mathrm{M} \mathrm{SIM}$ and $2 \mathrm{mM} \mathrm{MET} \pm 10 \mu \mathrm{M} z$-VAD-fmk pan-caspase inhibitor for $24-96 \mathrm{~h}, n=3$ per treatment group. NS denotes not significant difference in cell viability between the treatment groups of SIM+MET in presence or absence of $z$-VAD-fmk as determined by the two-tailed Student's $t$-test 
undergoing apoptosis at this time point. Therefore, we evaluated the potential of SIM+MET to induce cell death by apoptosis using methods to capture potential activation of mitochondrial (intrinsic) and/or death receptor signaling (extrinsic) apoptotic pathways. Caspase-3 and downstream poly-(ADP-ribose) polymerase (PARP) are cleaved and activated by both pathways of apoptosis. ${ }^{24}$ In distinct contrast to apoptosis-inducing positive control (S)-(+)-camptothecin treatment, neither caspase-3 nor PARP cleavage was noted following SIM+MET treatment for 24-72 h (Figure 3a).

One of the earliest features of apoptosis involves translocation of phosphatidylserine from the internal to external bilayer of the cell membrane; Annexin $\mathrm{V}(\mathrm{AV})$ demonstrates high specificity and affinity for phosphatidylserine. ${ }^{25}$ Necrotic cells can also bind AV due to damaged plasma membranes; therefore, $\mathrm{PI}$ is used to distinguish between apoptotic and necrotic cells, as it can only enter unfixed cells across a damaged plasma membrane. ${ }^{26}$ In a $\mathrm{PI} / \mathrm{AV}$ assay, $\mathrm{PI}(-) / \mathrm{AV}(+)$ cells are apoptotic, $\mathrm{PI}(+) / \mathrm{AV}(+)$ cells are either post-apoptotic secondary necrotic or primary necrotic, and $\mathrm{PI}(+) / \mathrm{AV}(-)$ cells are necrotic; AV-positivity precedes $\mathrm{PI}$-positivity in apoptotic cells, but coincides in necrotic cells (Supplementary Figures S1a and b). ${ }^{27}$ Following treatment with SIM+MET for 48-96 $\mathrm{h}$, the percentage of viable $\mathrm{PI}(-) / \mathrm{AV}(-)$ cells decreases significantly compared with untreated or individually treated cells; however, the percentage of $\mathrm{PI}(-) / \mathrm{AV}(+)$ cells remains low $(<4 \%)$, indicating $\mathrm{C} 4-2 \mathrm{~B}$ cells were not undergoing apoptosis (Figure $3 \mathrm{~b}$ and Supplementary Figure S1c). Rather, AV- and PI-positivity of C4-2B cells occur simultaneously, with majority of cells becoming significantly $\mathrm{PI}$ $(+) / A V(-)$, compared with untreated or individually treated cells. SIM+MET-treated C4-2B cells (21-24\%) are

a

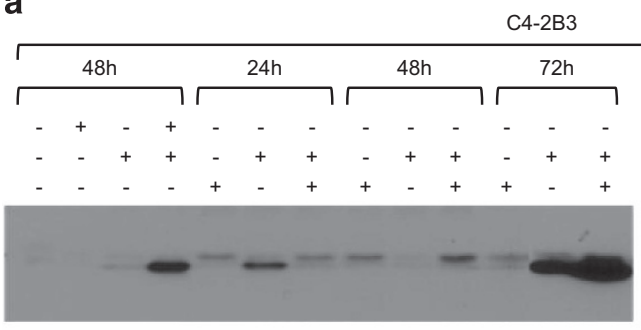

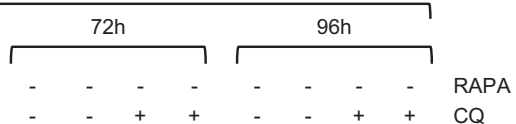

$\begin{array}{lllllllllllll}1.0 & 0.4 & 1.7 & 13 & 1.7 & 8.1 & 3.7 & 2.2 & 1.1 & 3.4 & 4.1 & 20 & 31\end{array}$
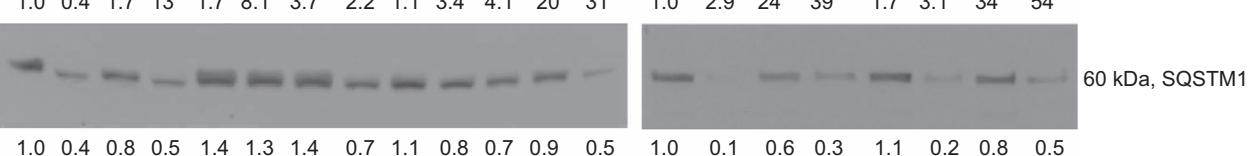

$\begin{array}{lllllllllllll}1.0 & 0.4 & 0.8 & 0.5 & 1.4 & 1.3 & 1.4 & 0.7 & 1.1 & 0.8 & 0.7 & 0.9 & 0.5\end{array}$

$\begin{array}{llllllll}1.0 & 0.1 & 0.6 & 0.3 & 1.1 & 0.2 & 0.8 & 0.5\end{array}$
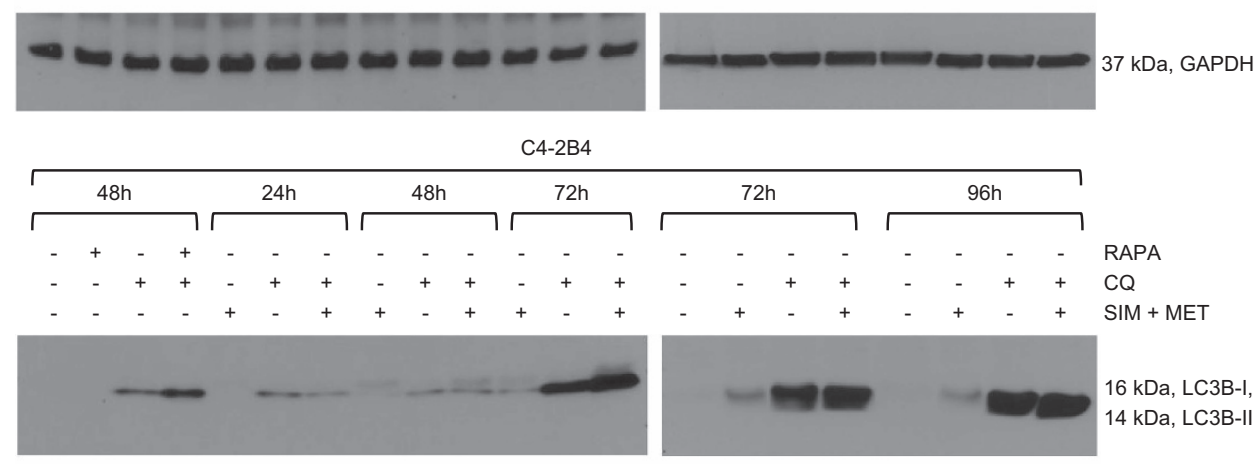

$\begin{array}{lllllllllllll}1.0 & 1.2 & 9.8 & 22 & 1.9 & 9.4 & 4.7 & 2.6 & 5.7 & 9.7 & 7.3 & 38 & 58\end{array}$
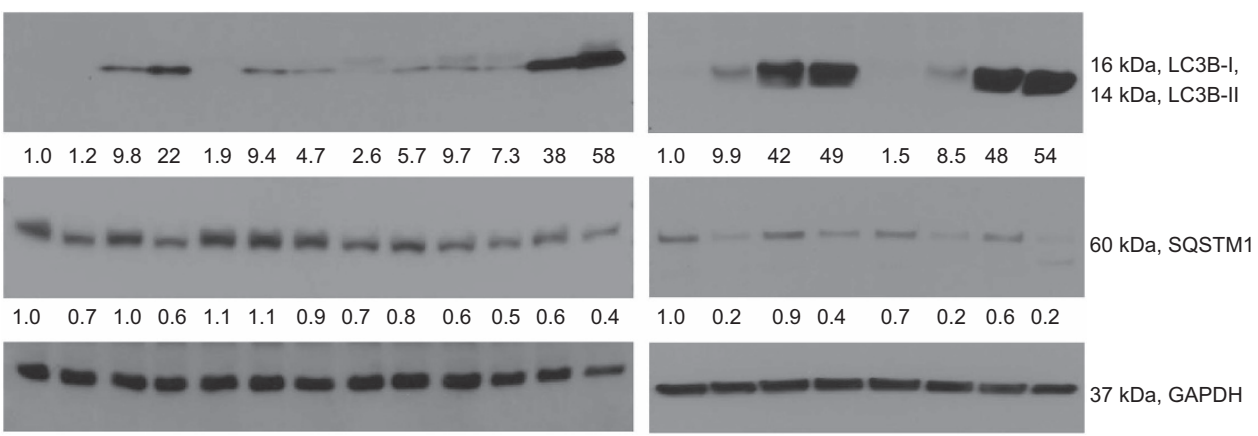

Figure 4 Combination simvastatin and metformin treatment increases autophagic flux in C4-2B metastatic CRPC cells. (a) Western blot analysis of LC3B-I and -II and sequestosome 1 (SQSTM1) protein expression in total cell lysates of C4-2B3 and C4-2B4 cells following treatment with combination $4 \mu \mathrm{M}$ simvastatin (SIM) and $2 \mathrm{mM}$ metformin (MET) and/or $10 \mu \mathrm{M}$ chloroquine (CQ) lysosomal inhibitor for $24-96 \mathrm{~h}$. Total cell lysates of C4-2B3 and C4-2B4 cells treated with 500nM rapamycin (RAPA) and/or $10 \mu \mathrm{M}$ CQ used as autophagic flux positive controls. GAPDH used as loading control. (b) Representative density plots of acidic vesicular organelles (AVOs) by acridine orange staining using flow cytometry in C4-2B3 and C4-2B4 cells treated with combination $4 \mu \mathrm{M}$ SIM and $2 \mathrm{mM} \mathrm{MET} \pm 10 \mu \mathrm{M} \mathrm{CQ}$ for $72 \mathrm{~h}$. In acridine orange-stained cells, the nucleus fluoresces green ( $F L 1,525 \mathrm{~nm}$ emission, $x$-axis), whereas acidic compartments fluoresce red ( $F L 3,620 \mathrm{~nm}$ emission, $y$-axis). The intensity of red fluorescence is proportional to the degree of acidity and to the volume of AVOs, including autophagic vacuoles. Insets show increase in red fluorescence (FL3, $x$-axis) with treatment compared with untreated control. (c) Quantification (mean \pm S.D.) of percentages of cells from each treatment group from $\mathbf{b}$ with a significant proportion of AVOs, $n=3$ separate experiments. ${ }^{*} P<0.05,{ }^{* *} P<0.01$, ${ }^{* \star *} P<0.001$ determined by a two-tailed Student's $t$-test compared with untreated control. Representative density plots and quantification of positive controls shown in Supplementary Figure S4 
$\mathrm{PI}(+) / \mathrm{AV}(-)$ and $\mathrm{PI}(+) / \mathrm{AV}(+)$ after $48 \mathrm{~h}$, progressing to $64-66 \%$ after the $96-\mathrm{h}$ treatment. Therefore, SIM+MET treatment does not induce apoptosis, but instead necrosis, markedly, by 72-96-h treatment.

As final confirmation that apoptosis is not the mode by which SIM+MET induces cell death in C4-2B cells, cells were treated with SIM+MET in presence and absence of $10 \mu \mathrm{M}$ z-VAD-fmk pan-caspase inhibitor for 24-96 h and viability assessed for rescue, which would indicate a caspase-dependent apoptotic cell death mechanism. The concentration $10 \mu \mathrm{M} z-V A D-f m k$ was chosen because it previously suppressed apoptosis in C4-2B cells without itself affecting viability ${ }^{28}$ and prevented caspase-3 and PARP cleavage in C4-2B cells treated with (S)(+)-camptothecin (Supplementary Figure S2). Shown in Figure 3c, apoptosis suppression with z-VAD-fmk provided no cell viability rescue. Despite a temporary spike in hypoploid cells at $48 \mathrm{~h}$ of SIM+MET treatment (which could be due to other oncosis), our results do not support apoptosis as a cytotoxic pathway induced by SIM+MET treatment in C4-2B cells.

CRPC cells upregulate autophagy in an attempt to withstand SIM+MET chemotherapy. Macroautophagy (hereafter referred to as autophagy) is a lysosomaldependent process of self-digestion of cytoplasmic content regulated by AMPK that can have a role in mediating either cell survival or death in response to nutrient starvation and stress. $^{29}$ Both SIM and MET can induce autophagy in prostate and other cancers. ${ }^{15,17}$ We previously demonstrated that SIM+MET inhibit Akt phosphorylation and activity and reactivate AMPK activity in C4-2B cells; ${ }^{10}$ inhibition of Akt and activation of AMPK in cancer cells often leads to

b

b UNT
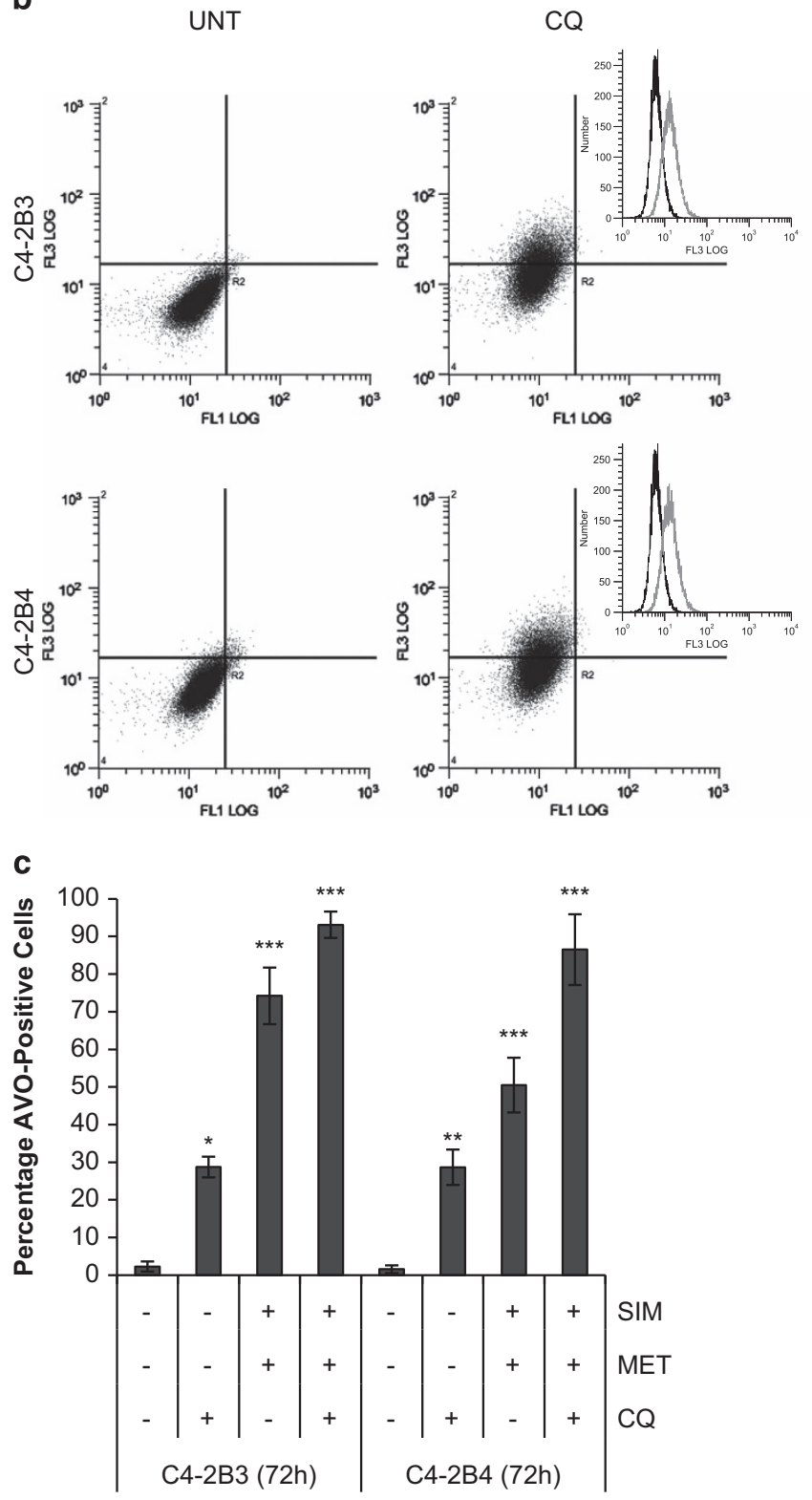

$\mathrm{SIM}+\mathrm{MET}$
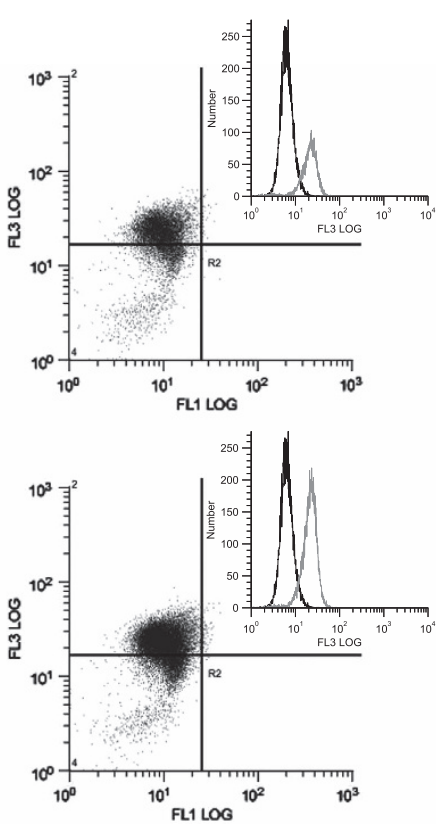
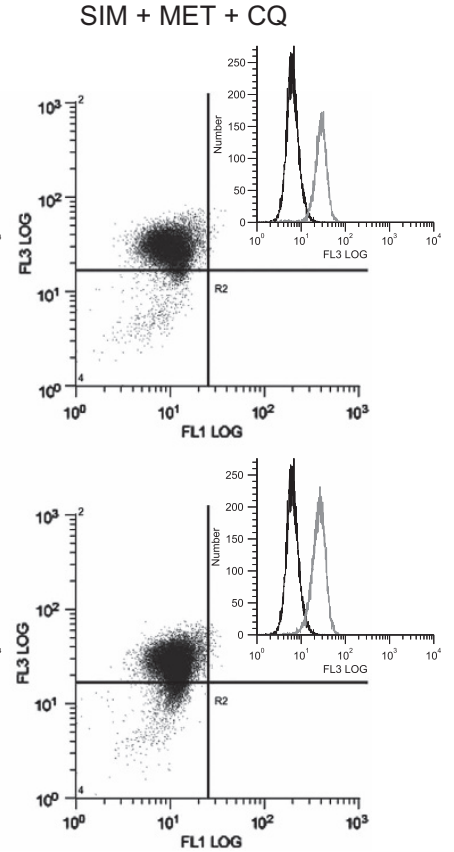

Figure 4 (Continued) 


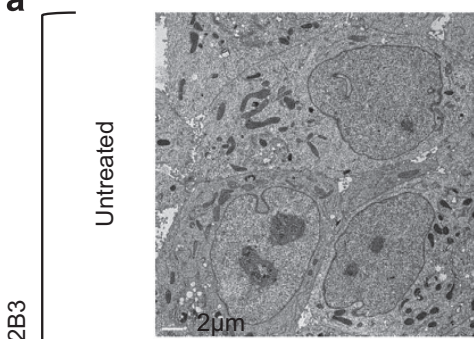

ठ̛
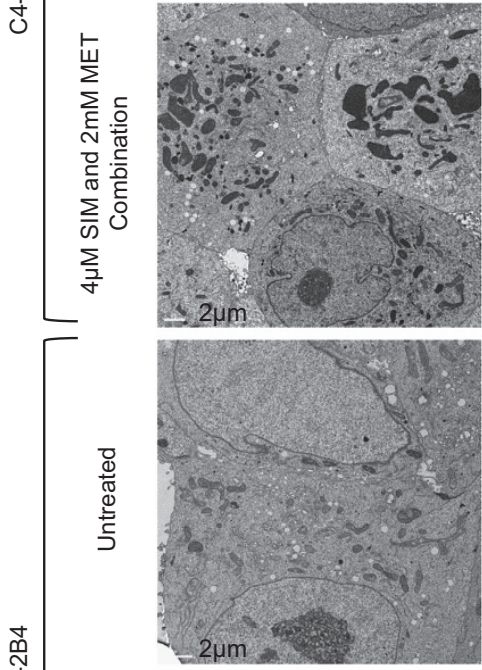

ठ

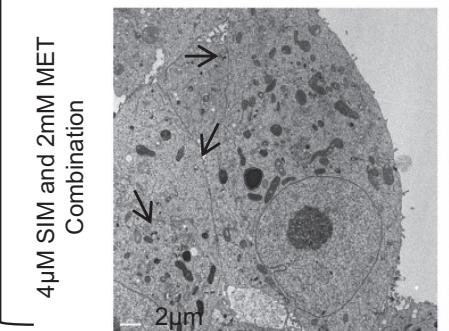

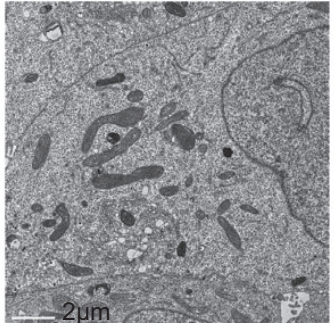
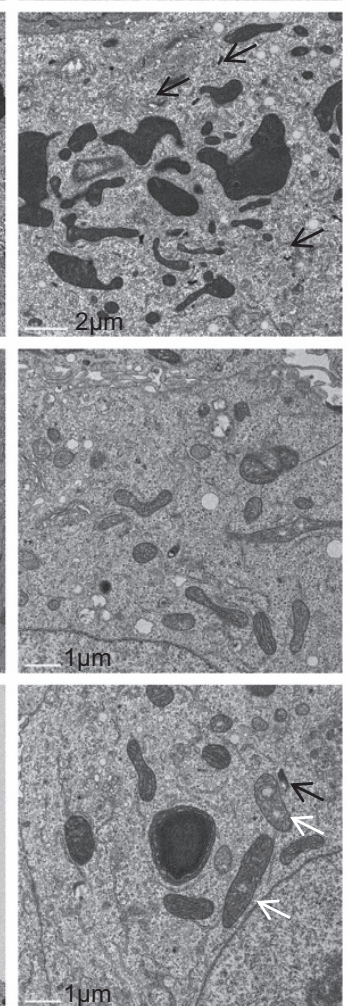
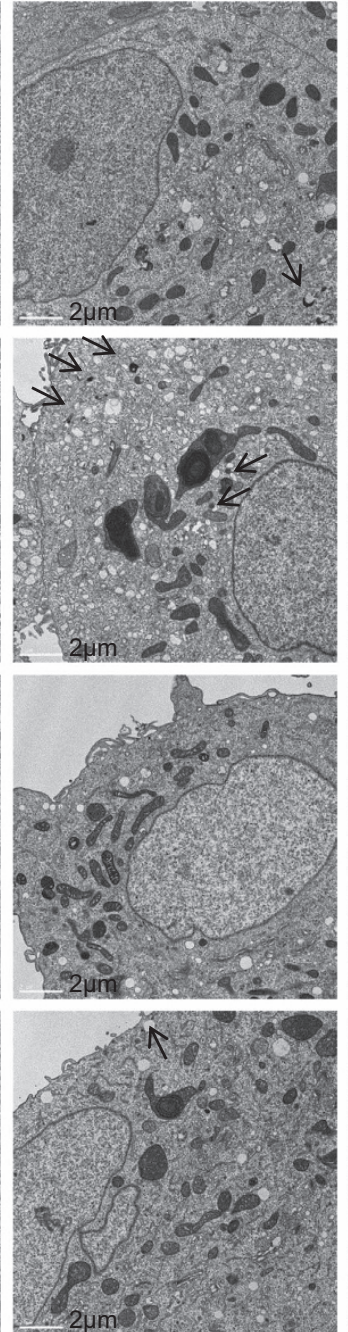
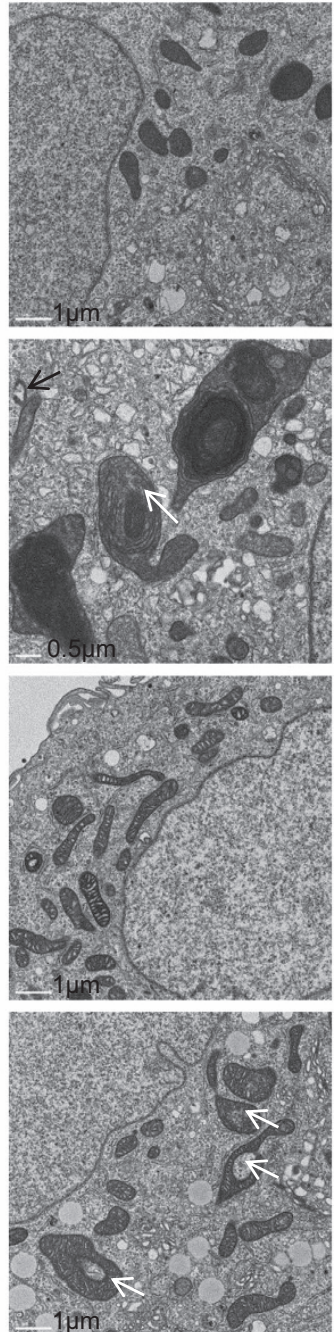

b

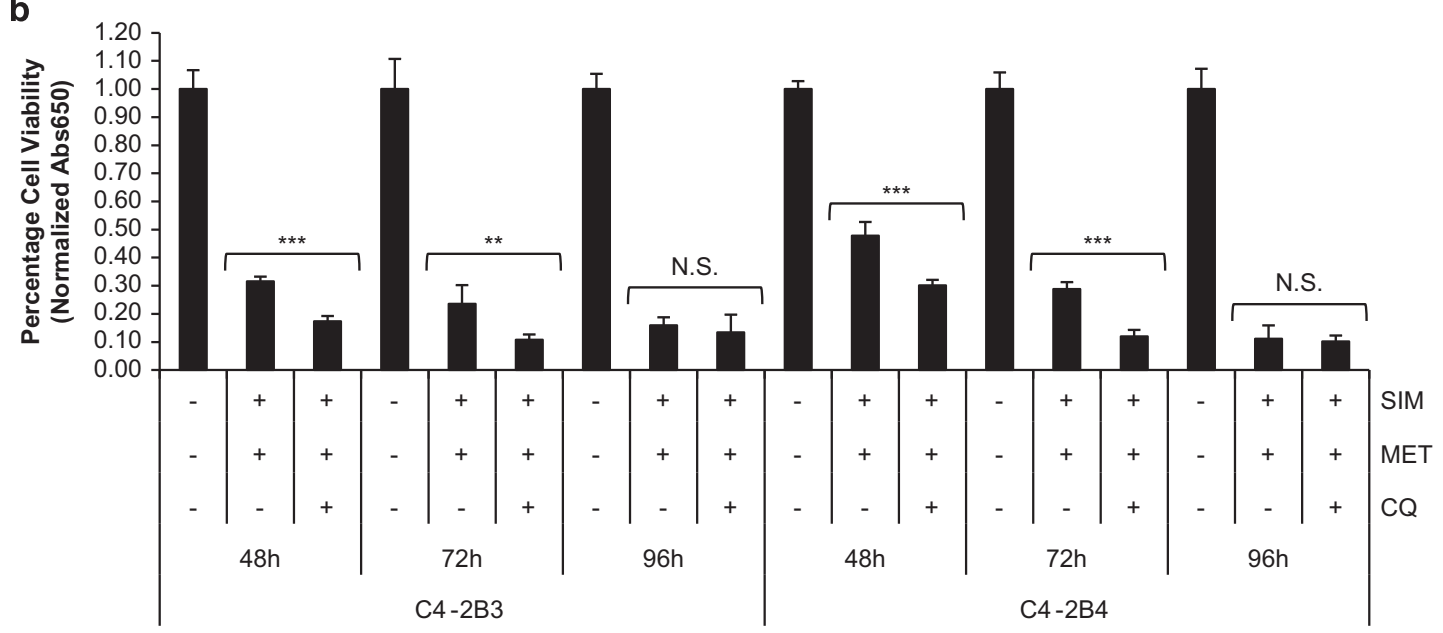

Figure 5 C4-2B metastatic CRPC cells upregulate autophagy as a protective mechanism against combination simvastatin and metformin treatment. (a) Transmission electron microscopy pictures of untreated and combination $4 \mu \mathrm{M}$ simvastatin (SIM) and $2 \mathrm{mM}$ metformin (MET)-treated C4-2B3 and C4-2B4 cells at 72 h. Black arrows show double-membrane degradative (i.e., lysosome associated with vesicle) and lucent autophagic vesicles. White arrows show potentially mitoptotic mitochondria. Scale bar noted on images. (b) Percentage cell viability (mean \pm S.D.) by methylene blue in C4-2B3 and C4-2B4 cells following treatment with combination $4 \mu \mathrm{M} \mathrm{SIM} \mathrm{and} 2 \mathrm{mM}$ MET $\pm 10 \mu \mathrm{M}$ chloroquine (CQ) lysosomal inhibitor for $48-96 \mathrm{~h}, n=3$ per group. ${ }^{* *} \mathrm{P}<0.01,{ }^{* * *} \mathrm{P}<0.001$, and NS $=$ no significant difference between treatment groups of SIM+MET in presence or absence of $C Q$, as determined by the two-tailed Student's $t$-test 
autophagy. ${ }^{30}$ Therefore, we next investigated autophagy as a potential mechanism by which SIM+MET induces cell death in C4-2B metastatic CRPC cells.
During autophagy, a phagophore engulfs a portion of cytoplasm containing organelles and proteins and encloses, forming an autophagosome, which then joins with a lysosome a

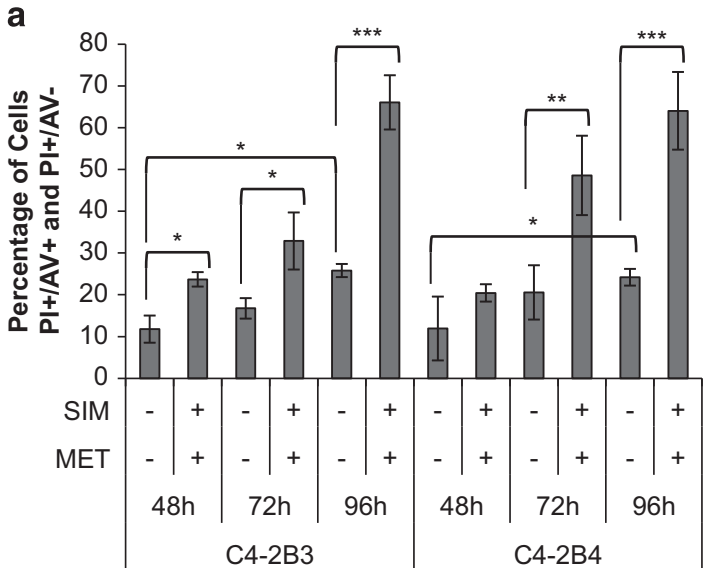

C
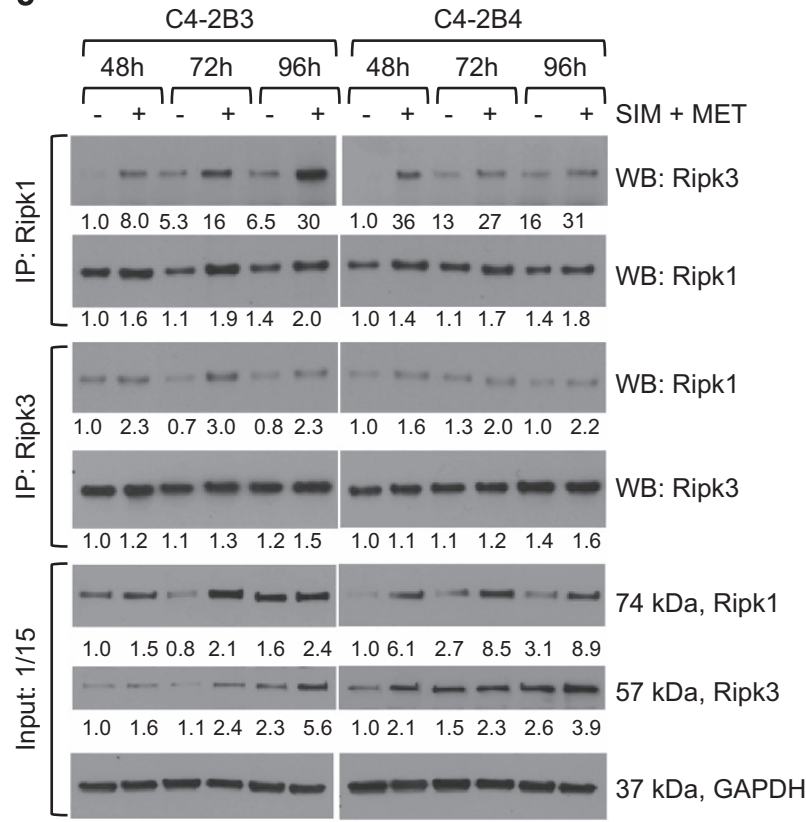

b

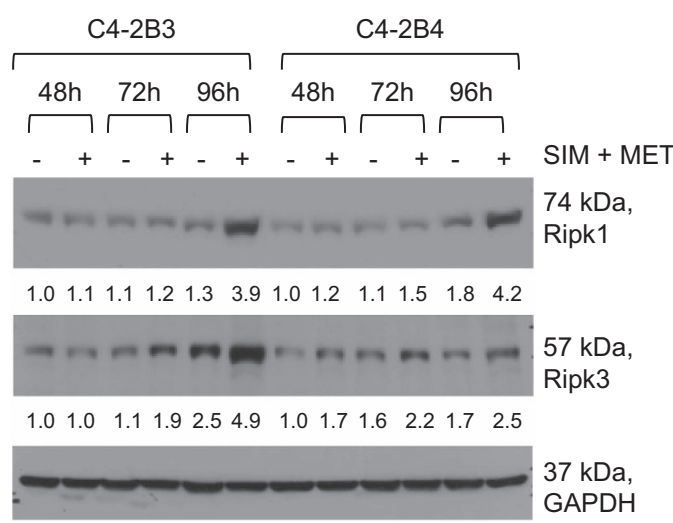

e

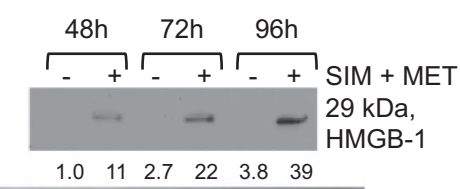

C4-2B3

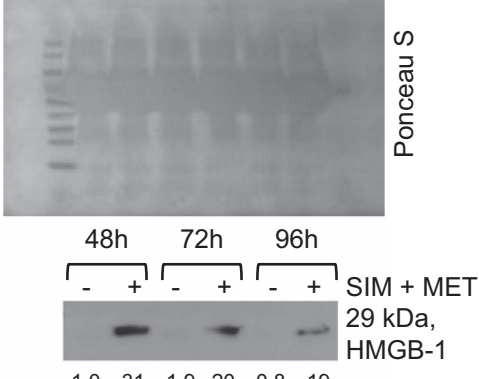

C4-2B4

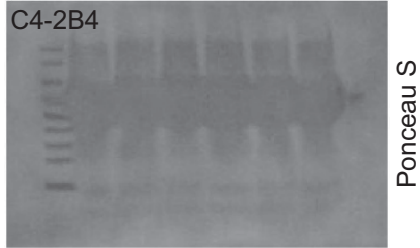

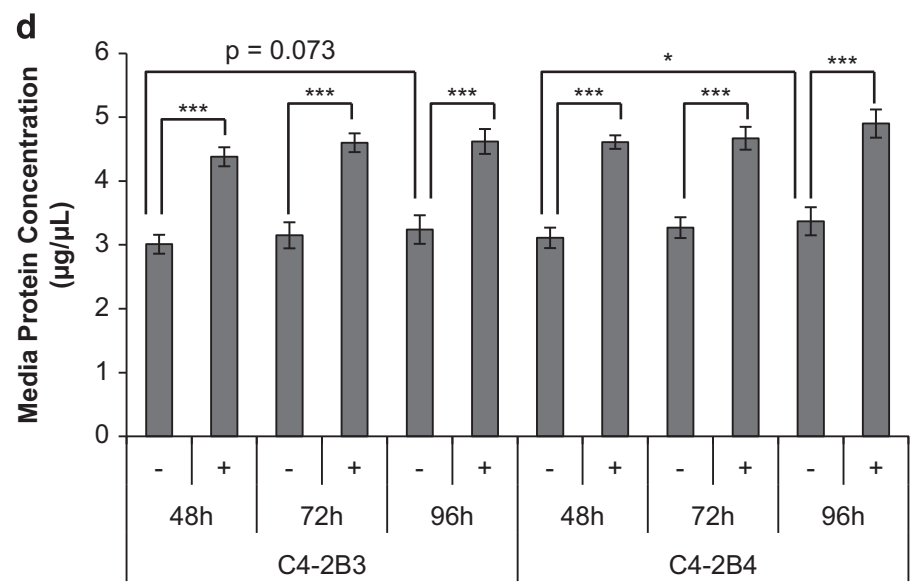


to form an autolysosome where contents are digested into reusable macromolecules. ${ }^{31,32}$ Microtubule-associated protein 1 light chain 3 (LC3) is utilized as a marker of autophagic activity. $^{32-34}$ There are three human isoforms of LC3, LC3A-C, which undergo post-translational modification during autophagy; LC3B being the homolog most commonly used to assess autophagy. ${ }^{33,34}$ Following an autophagic trigger, cytosolic LC3B-I is conjugated with phosphatidylethanolamine $(\mathrm{PE})$ to form LC3B-II, which is recruited to and detected on autophagosomal membranes. ${ }^{32-34}$ The quantity of LC3B-II is not static; during autophagosome formation, outer membrane LC3B-II is cleaved from PE by Atg4 to replenish available cytoplasmic LC3B-I and inner membrane LC3B-II degraded along with cargo within the autolysosome. ${ }^{33}$ LC3B-II protein expression is positively correlated with number of autophagosomes, and increase in LC3B-II is an indicator of autophagosome formation (autophagic flux). ${ }^{33,34}$ However, increase in LC3B-II protein can also indicate inhibition of autolysosomal function. $^{33,34}$ To determine whether LC3B-II expression increases due to autophagic flux or autolysosomal function inhibition, a lysosomal inhibitor, such as chloroquine (CQ), is used. ${ }^{34} \mathrm{CQ}$ is a lysosomotropic agent that becomes trapped within the lysosome due to protonation, and raises lysosomal $\mathrm{pH}$, which inhibits lysosomal enzymes, prevents fusion of autophagosome and lysosome, and prevents lysosomal protein degradation. Therefore, an equivalent quantity of LC3B-II protein following SIM+MET treatment in presence and absence of $\mathrm{CQ}$ demonstrates inhibition of autolysosomal function, whereas enhanced LC3B-II accumulation in presence of $\mathrm{CQ}$ demonstrates that SIM+MET treatment induces autophagic flux. Shown in Figure $4 \mathrm{a}$, LC3B-II accumulation is observed at 72-96-h SIM+MET treatment, but is only lightly visible due to LC3B-II recycling and degradation within the autolysosome. Yet, LC3B-II accumulation is greatly enhanced with SIM+MET treatment in presence of $\mathrm{CQ}$, indicating that $\mathrm{SIM}+\mathrm{MET}$ treatment induces autophagic flux, in a similar manner as positive control rapamycin-induced autophagy. The dosage $10 \mu \mathrm{M}$ $\mathrm{CQ}$ was chosen for ability to effectively inhibit autolysosome function without itself significantly affecting C4-2B cell viability (Supplementary Figures $\mathrm{S} 3 \mathrm{a}$ and $\mathrm{b}$ ). Another protein monitored to detect autophagic flux is sequestosome 1 (SQSTM1/p62), a scaffold protein that binds both ubiquitin and LC3B-II, and is integral in transport of ubiquitin-tagged protein aggregates to the autophagosome. ${ }^{34,35}$ SQSTM1 is degraded along with cytoplasmic material within the autolysosome, leading to decreased SQSTM1 protein levels during autophagy. ${ }^{34,35}$ As seen in Figure 4a, SQSTM1 protein markedly decreases following SIM+MET treatment for $72-96 \mathrm{~h}$, and is partially rescued in presence of lysosomal inhibitor $\mathrm{CQ}$, providing additional evidence of autophagic flux induction in response to SIM+MET treatment.

An increase in the number of acidic vesicular organelles (AVOs), or intracellular acidic compartments such as autolysosomes and lysosomes, is also characteristic of autophagy. ${ }^{36}$ Acridine orange $(\mathrm{AO})$ is an acidotropic dye that accumulates in AVOs and fluoresces bright red when protonated at low $\mathrm{pH}$; the intensity of red fluorescence is proportional to the volume of AVOs and is quantified by flow cytometry (normalized to green fluorescence of AO-stained DNA/RNA). ${ }^{36}$ Autophagic induction following SIM+MET treatment for $72 \mathrm{~h}$ was confirmed by significantly increased percentage of AVO-positive C4-2B cells, which was further enhanced in presence of $\mathrm{CQ}$, again indicating enhanced autophagic flux in response to SIM+MET treatment (Figures $4 \mathrm{~b}$ and $\mathrm{c}$ ) (percentage of AVO-positive cells in rapamycin $\pm \mathrm{CQ}$-treated C4-2B3/B4 positive controls quantified in Supplementary Figure S4). In addition, transmission electron microscopy (TEM) revealed an accumulation of double-membrane degradative (lysosomes associated with vesicle, black arrows) and autophagic vesicles in C4-2B3/B4 cells following SIM+MET treatment for $72 \mathrm{~h}$ (Figure $5 \mathrm{a}$ ).

Autophagy can be a mechanism of cell death; however, cancer cells also upregulate autophagy in an effort to withstand nutrient deprivation and potentially cytotoxic insults of drug treatment as a mechanism of chemoresistance. ${ }^{37}$ To determine whether the increase in autophagic flux observed in C4-2B cells following SIM+MET treatment for 72-96 $\mathrm{h}$ is an attempt to withstand chemotherapeutic insult or is part of the mechanism by which SIM+MET treatment induces C4-2B cell death, we sought to investigate whether autophagic inhibitor $\mathrm{CQ}$ could rescue C4-2B cell viability inhibition induced by SIM+MET treatment. Should CQ rescue viability, then autophagy is part of the cell death process induced by SIM+MET (i.e., autophagy-mediated necrotic cell death ${ }^{38}$ ), whereas lack of rescue or further reduction in $\mathrm{C} 4-2 \mathrm{~B}$ viability upon addition of $C Q$ implies autophagy upregulated in C4-2B cells in attempt at cellular defense against SIM+MET chemotherapy. Following treatment with SIM+MET in presence of $C Q, C 4-2 B$ cell viability was significantly further reduced at $48-72 \mathrm{~h}$ and unrescued at $96 \mathrm{~h}$ compared with viability in absence of $\mathrm{CQ}$ (Figure $5 \mathrm{~b}$ ); therefore, autophagy is upregulated by $\mathrm{C} 4-2 \mathrm{~B}$ cells following SIM+MET treatment as a mechanism of chemoresistance, but is not part of the cell death process.

Figure 6 Combination simvastatin and metformin treatment induces necrotic cell death in C4-2B metastatic CRPC cells. (a) $\mathrm{C} 4-2 \mathrm{~B} 3$ and $\mathrm{C} 4-2 \mathrm{~B} 4$ cells treated with $4 \mu \mathrm{M}$ simvastatin (SIM) and $2 \mathrm{mM}$ metformin (MET) for $48-96 \mathrm{~h}$ followed by staining with FITC-conjugated Annexin V (AV) and propidium iodide (PI) and analyzed by flow cytometry. Percentage of cells (mean \pm S.D.) staining $\mathrm{Pl}+(\mathrm{PI}(+) \mathrm{AV}(+)$ and $\mathrm{PI}(+) \mathrm{AV}(-))$ depicted in bar graphs, $n=3$ separate cytometric experiments. ${ }^{*} P<0.05$, ${ }^{* \star} P<0.01$, ${ }^{* \star *} P<0.001$ determined by ANOVA followed by the Tukey multiple comparison procedure. (b) Western blot analysis of Ripk1 and Ripk3 protein expression in total cell lysates of C4-2B3 and C4-2B4 cells following treatment with combination $4 \mu \mathrm{M}$ SIM and $2 \mathrm{mM}$ MET for $48-96 \mathrm{~h}$. GAPDH used as loading control. (c) Treatment of C4-2B3 and C4-2B4 cells with combination $4 \mu \mathrm{M}$ SIM and $2 \mathrm{mM}$ MET for $48-96 \mathrm{~h}$ induces association of Ripk1 and Ripk3 in a time-dependent manner. Immunoprecipitation of $600 \mu \mathrm{g}$ protein from total cell lysates was conducted with Ripk1 and Ripk3 antibodies followed by western blot with Ripk1, Ripk3, and GAPDH antibodies. No GAPDH detected in immunoprecipitates (not shown). Forty $\mu \mathrm{g}$ protein from total cell lysates were also immunoblotted as a control (input). Protein expression was quantified by densitometry normalized to GAPDH loading control (mean from two separate experiments). (d) Protein concentration (mean \pm S.D.) of conditioned media from C4-2B3 and C4-2B4 cells following treatment with combination $4 \mu \mathrm{M}$ SIM and $2 \mathrm{mM}$ MET for $48-96 \mathrm{~h}, n=3$ separate experiments. ${ }^{*} P<0.05,{ }^{* * *} P<0.001$ determined by ANOVA followed by the Tukey multiple comparison procedure. (e) Western blot analysis of HMGB-1 protein in $40 \mu$ l conditioned media from C4-2B3 and C4-2B4 cells following treatment with combination $4 \mu \mathrm{M}$ SIM and $2 \mathrm{mM}$ MET for $48-96 \mathrm{~h}$. HMGB-1 protein expression quantified by densitometry (mean from two separate experiments). Ponceau S stain used to demonstrate equal loading 
a

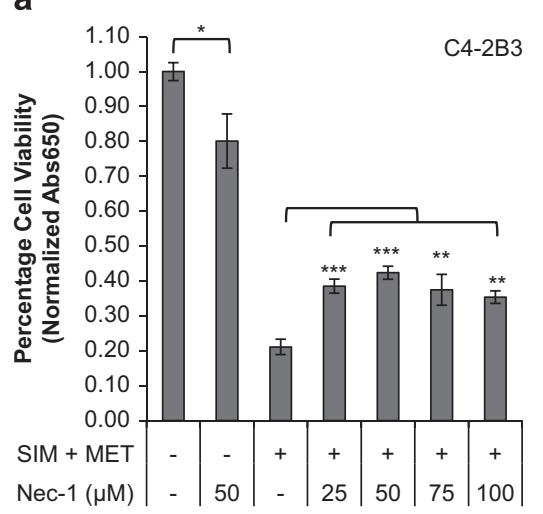

b

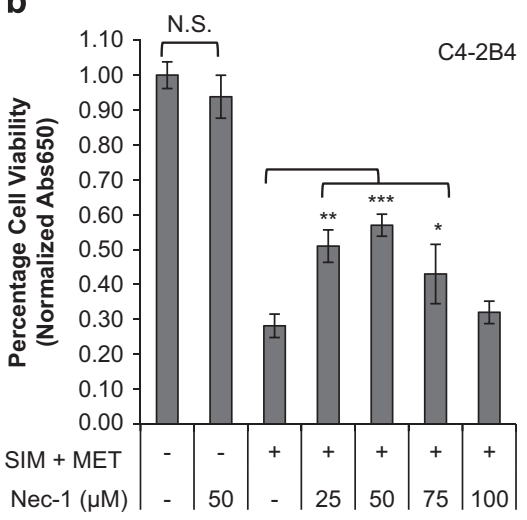

c

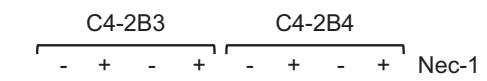

$\begin{array}{llllllll}- & + & + & - & + & + & \mathrm{NeC}-1 \\ - & + & + & - & + & + & \mathrm{SIM}+\mathrm{MET}\end{array}$

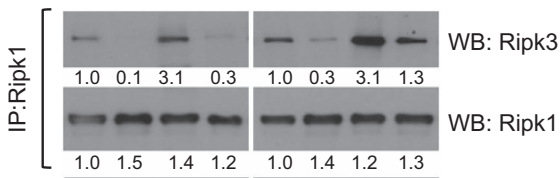

m [ - - - - - - WB: Ripk1

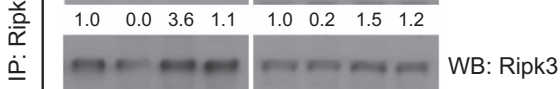

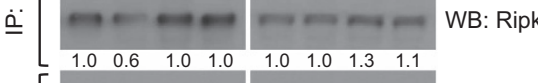

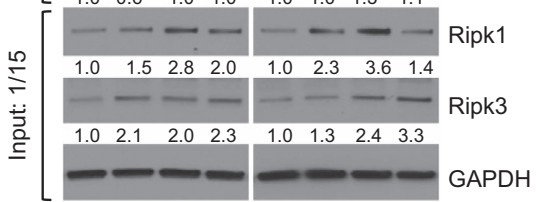

d
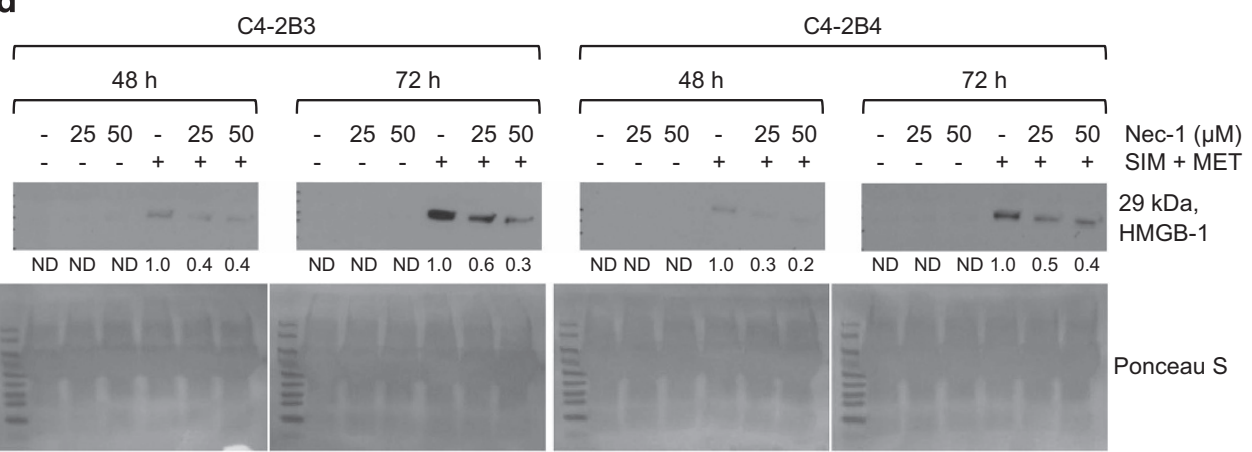

Figure 7 SIM+MET-induced necrosis in C4-2B metastatic CRPC cells is in part Ripk1 dependent. (a,b) Percentage cell viability (mean \pm S.D.) by the methylene blue assay in C4-2B3 and C4-2B4 cells following treatment with $50 \mu \mathrm{M}$ Ripk1 inhibitor necrostatin-1 (Nec-1) or combination $4 \mu \mathrm{M}$ simvastatin (SIM) and 2 mM metformin (MET) $\pm 25-100 \mu \mathrm{M}$ Nec-1 for $72 \mathrm{~h}, n=3$ separate experiments. ${ }^{*} P<0.05,{ }^{* *} P<0.01,{ }^{* \star *} P<0.001$, NS $=$ not significant, as determined by ANOVA followed by the Tukey multiple comparison procedure. (c) Treatment of C4-2B3 and C4-2B4 cells with $50 \mu \mathrm{M} \mathrm{Nec}-1$ for $72 \mathrm{~h}$ reduces Ripk1-Ripk3 association. Immunoprecipitation of $600 \mu \mathrm{g}$ protein from total cell lysates of C4-2B3 and C4-2B4 cells treated with $50 \mu \mathrm{M} \mathrm{Nec-1}$ and/or combination $4 \mu \mathrm{M}$ SIM and $2 \mathrm{mM}$ MET was conducted with Ripk1 and Ripk3 antibodies followed by western blot with Ripk1, Ripk3, and GAPDH antibodies. No GAPDH detected in immunoprecipitates (not shown). Protein $(40 \mu \mathrm{g})$ from total cell lysates were also immunoblotted as a control (input). Protein expression was quantified by densitometry normalized to GAPDH loading control (mean from two separate experiments). (d) Western blot analysis of HMGB-1 protein in $40 \mu$ l conditioned media from C4-2B3 and C4-2B4 cells following treatment with $25-50 \mu \mathrm{M} \mathrm{Nec}-1$ or combination $4 \mu \mathrm{M} \mathrm{SIM}$ and $2 \mathrm{mM} \mathrm{MET} \pm 25-50 \mu \mathrm{M}$ Nec-1 for $48-72 \mathrm{~h}$. HMGB-1 protein expression quantified by densitometry (mean from two separate experiments). ND, none detected. Ponceau $\mathrm{S}$ stain used to demonstrate equal loading

SIM+MET treatment induces necrotic cell death in CRPC cells. We demonstrated through PI/AV assessment (Figures $3 \mathrm{~b}$ and $6 \mathrm{a}$,Supplementary Figure S1c) that SIM+MET treatment led to significant increase in $\mathrm{PI}(+) \mathrm{C} 4-2 \mathrm{~B}$ cells by
$48-96 \mathrm{~h}$; in fact, at the $96-\mathrm{h}$ combination treatment, $61-64 \%$ of $\mathrm{C} 4-2 \mathrm{~B}$ cells were either $\mathrm{PI}(+) / \mathrm{AV}(-)$ or $\mathrm{PI}(+) / \mathrm{AV}(+)$, strongly implicating necrosis as the primary cell death process associated with SIM+MET treatment in C4-2B cells. 
SIM treatment was shown to induce necrotic cell death in cancer cells, including prostate cancer, albeit at supraphysiological concentrations of inactivated SIM. ${ }^{14,39}$ Necrosis is cell death in response to external factors, characterized by cell clumping and swelling ( $\mathrm{C} 4-2 \mathrm{~B}$ cells are clumped and swollen at 48-72-h SIM+MET treatment in Figure 1b), protein denaturation, nuclear membrane, organelle, and plasma membrane disruption, and release of cellular material into extracellular space. ${ }^{29}$ Necrosis was recently discovered to be a regulated mode of cell death of which the central mediators are serine-threonine kinases receptor-interacting protein 1 (Ripk1) and Ripk3. ${ }^{29,40}$ Upon the necrosisstimulating trigger, Ripk1 and Ripk3 bind one another, are phosphorylated and activated, form a complex with caspase-8, FADD, and other proteins, called a necrosome, and necrosis is induced. ${ }^{29,41,42}$

To confirm SIM+MET induces necrotic cell death in C4-2B cells, we first investigated the effect of SIM+MET treatment on protein expression of Ripk1 and Ripk3, as expression of these kinases increases as cells undergo necrosis. ${ }^{43}$ Shown in Figure 6b, both Ripk1 and Ripk3 protein expression increased in C4-2B cells following combination treatment for $72-96 \mathrm{~h}$. To confirm Ripk1-Ripk3 interaction and necrosome formation, Ripk1 and Ripk3 were immunoprecipitated from C4-2B3/B4 whole-cell lysates following SIM+MET treatment for $48-96 \mathrm{~h}$; increased co-precipitation of Ripk1 and Ripk3 was found in both $\mathrm{C} 4-2 \mathrm{~B}$ strains following combination treatment (Figure 6c). Cells undergoing necrosis release large quantities of protein into the extracellular space. ${ }^{27,44}$ A $42-48 \%$ increase in protein concentration of conditioned media from C4-2B cells treated with SIM+MET for 48 - $96 \mathrm{~h}$ was observed compared with untreated cells (Figure 6d), indicative of largescale protein release possibly related to necrotic induction. Immunoblotting of conditioned media also revealed readily detected high-mobility group box-1 (HMGB-1) protein following SIM+MET treatment for 48 - $96 \mathrm{~h}$ (Figure 6e); HMGB-1 is nuclear-localized in viable cells, but released extracellularly during necrotic rupture. ${ }^{27}$ Of note, a basal level of necrotic characteristics exists in C4-2B cells; $11.8-25.8 \%$ of untreated cells are $\mathrm{PI}(+)$, significantly increasing with time (Figure 6a), and Ripk1 and Ripk3 protein expression (Figure 6b) and necrosome formation (Figure 6c) also increases throughout the timecourse in untreated cells.

SIM+MET-induced necrosis in CRPC cells is Ripk1- and Ripk3 dependent. Ripk1 and Ripk3 can be mutually or individually responsible for necrotic induction, ${ }^{45-47}$ so we next determined whether SIM+MET-induced necrosis was Ripk1and/or Ripk3 dependent using necrostatin-1 (Nec-1), a Ripk1 activity inhibitor, and siRNA to knockdown Ripk3 expression (resulted in average $62-67 \%$ knockdown of Ripk3 protein expression at $48 \mathrm{~h}$ and $56-66 \%$ knockdown at $72 \mathrm{~h}$ ). Nec-1, in a dose-dependent manner to $50 \mu \mathrm{M}$, partially rescued C4$2 \mathrm{~B}$ viability from the effect of SIM+MET treatment at $72 \mathrm{~h}$ (Figures $7 \mathrm{a}$ and b); however, efficacy of $\mathrm{Nec}-1$ rescue was lost at subsequent higher dosages. In fact, treatment of C42B3 cells with $50 \mu \mathrm{M} \mathrm{Nec-1}$ significantly decreased viability by $20 \%$ (Figure $7 a$ ); Ripk1 activity inhibition may affect cell survival because of Ripk1 important role as a common link in apoptotic, necrotic, and survival signaling pathways. ${ }^{48} \mathrm{Nec}-1$ also effectively inhibited Ripk1-Ripk3 co-precipitation (Figure 7c) and HMGB-1 extracellular release into conditioned media in a dose-dependent manner (Figure 7d). In siScramble- or siRipk3-transfected C4-2B cells, Nec-1 and Ripk3 knockdown each partially rescued C4-2B viability by $18-23 \%$ and $11-17 \%$, respectively (Figure $8 a$ ); yet, when Ripk3 protein expression and Ripk1 activity were simultaneously inhibited, it resulted in highly significant $36-42 \%$ rescue of C4-2B cell viability from the effect of SIM+MET treatment for $72 \mathrm{~h}$. Simultaneous Ripk3 protein expression and Ripk1 activity inhibition also effectively inhibited Ripk1Ripk3 co-precipitation (Figure 8b) and HMGB-1 release (Figure $8 \mathrm{c}$ ) in a time-dependent manner, with a combined effect on the inhibition of SIM+MET-induced necrosis greater than either Ripk3 siRNA or Nec-1 alone, indicative of a Ripk1and Ripk3-dependent necrotic cell death mechanism.

\section{Discussion}

We determined that SIM+MET treatment in C4-2B metastatic CRPC cells induces sustained G1-phase cell cycle arrest (24-96 h) leading to Ripk1- and Ripk3-dependent necrotic cell death by $72-96 \mathrm{~h}$. In addition, autophagy is upregulated in C4-2B cells by $72-96 \mathrm{~h}$ of SIM+MET treatment as a mode of chemoresistance. From a metabolic standpoint, the mode of cell death induced by SIM+MET in C4-2B cells is sensible.

SIM+MET treatment inhibits Akt phosphorylation and activity in C4-2B cells, which decreases inhibitory Ser$485 / 491$ phosphorylation on $\mathrm{AMPK} a_{1} / a_{2}$ and reactivates AMPKa. ${ }^{10}$ In addition, MET indirectly activates AMPK by mitochondrial complex I inhibition and decrease of cellular ATP $^{12}$ and SIM activates AMPK by depletion of cellular geranylgeranyl diphosphate. ${ }^{30}$ SIM+MET treatment and subsequent AMPK activation inhibits aerobic glycolysis and macromolecule synthesis, $, 10,49$ impeding CRPC growth, proliferation, and metastasis. ${ }^{5,10}$ The lack of nutrients starves the C4-2B CRPC cell, and prevents progression beyond the G1-phase cell cycle checkpoint, leading to G1-phase cell cycle arrest.

After prolonged AMPK activation and starvation, autophagy, as a protective mechanism, and cell death are triggered. ${ }^{50} \mathrm{C} 4-$ $2 \mathrm{~B}$ cells were shown to be resistant to extrinsic apoptotic cell death (i.e., TNFR-family-induced apoptotic cell death) due to loss of tumor necrosis factor receptor-associated death domain (TRADD) mRNA and protein expression. ${ }^{51}$ Loss of TRADD expression may explain why $C 4-2 B$ cells are resistant to docetaxel-induced cell death, ${ }^{10}$ as taxanes induce death receptor-mediated apoptotic cell death, ${ }^{52}$ and may also explain why we did not observe apoptotic induction in C4-2B cells following SIM+MET treatment. It has been demonstrated that if an apoptotic block exists downstream of death receptors, activation instead leads to necrosis, ${ }^{48,53}$ since Ripk1, a scaffold protein associated with death receptors, links survival, apoptosis, and necrosis pathways. ${ }^{48}$ If death receptors are triggered and apoptosis blocked, Ripk1 and Ripk3 bind one another, form the necrosome, and induce necrotic cell death, ${ }^{29,41,42,48}$ as was observed with SIM+MET treatment in C4-2B cells. Although the spike of hypoploid cells at the 48-h combination treatment is interesting, our results do not support apoptosis as a cytotoxic pathway induced by 
SIM+MET treatment in C4-2B cells. Sub-G1 cells could be caused by another oncosis, perhaps from the necrosis effect on surrounding cells, nuclear fragments, clusters of chromosomes, micronuclei, or nuclei with normal DNA content but altered chromatin structure and diminished accessibility of PI fluorochrome to DNA. ${ }^{54-56}$ Also interesting,

a

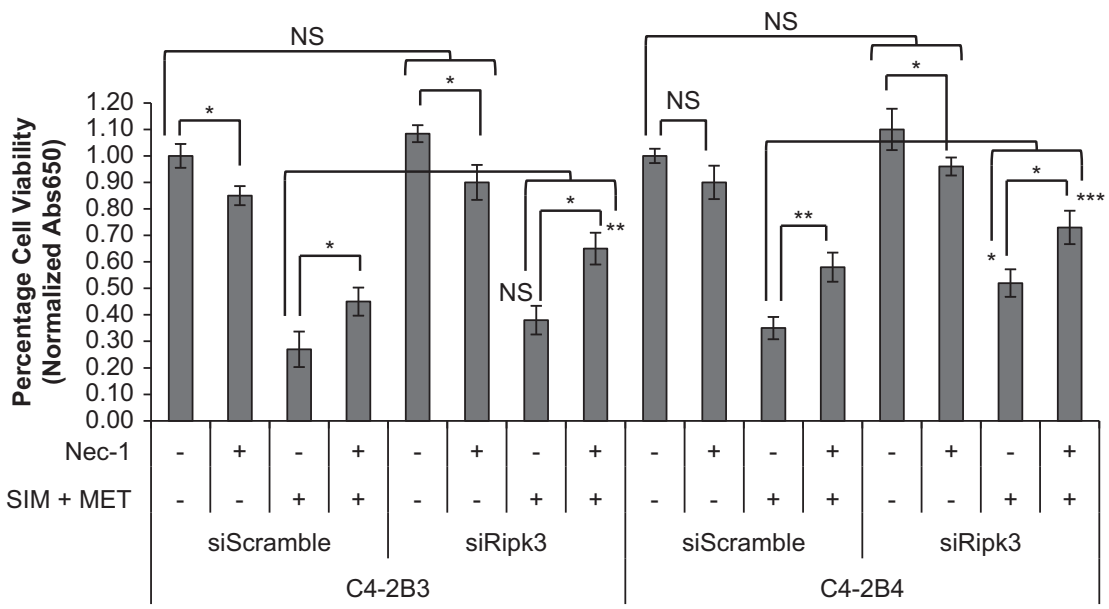

b

C4-2B3
$48 \mathrm{~h}$

$\overbrace{48 \mathrm{~h}}^{\mathrm{C} 4-2 \mathrm{~B}}$

\section{B4}

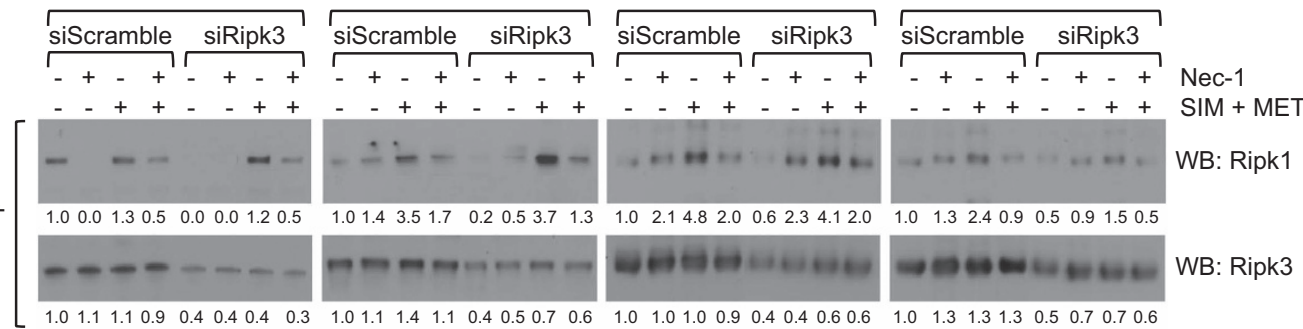

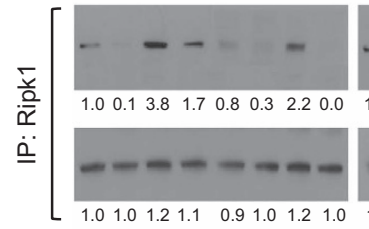
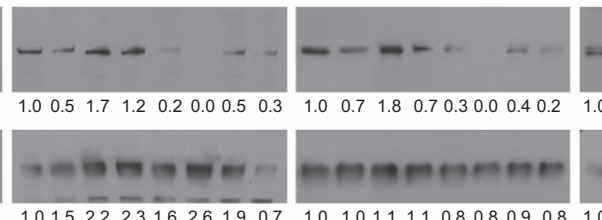

- $50-0$

WB: Ripk3
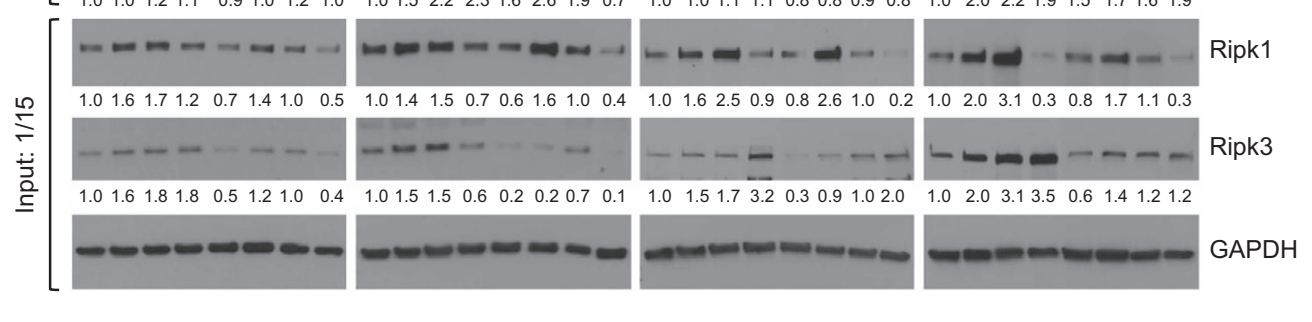

C

C4-2B3

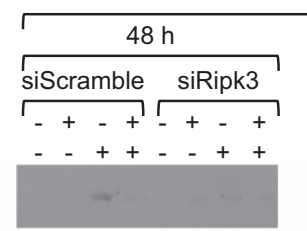

siScramble siRipk3

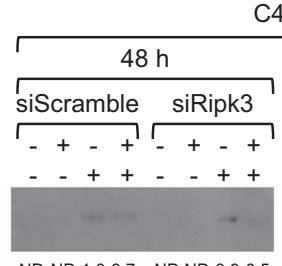

C4-2B4

ND ND 1.00 .2 ND ND 0.30 .1

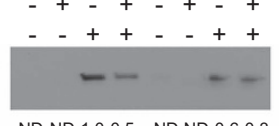

ND ND 1.00 .5 ND ND 0.60 .3

ND ND 1.00 .7 ND ND 0.90 .5
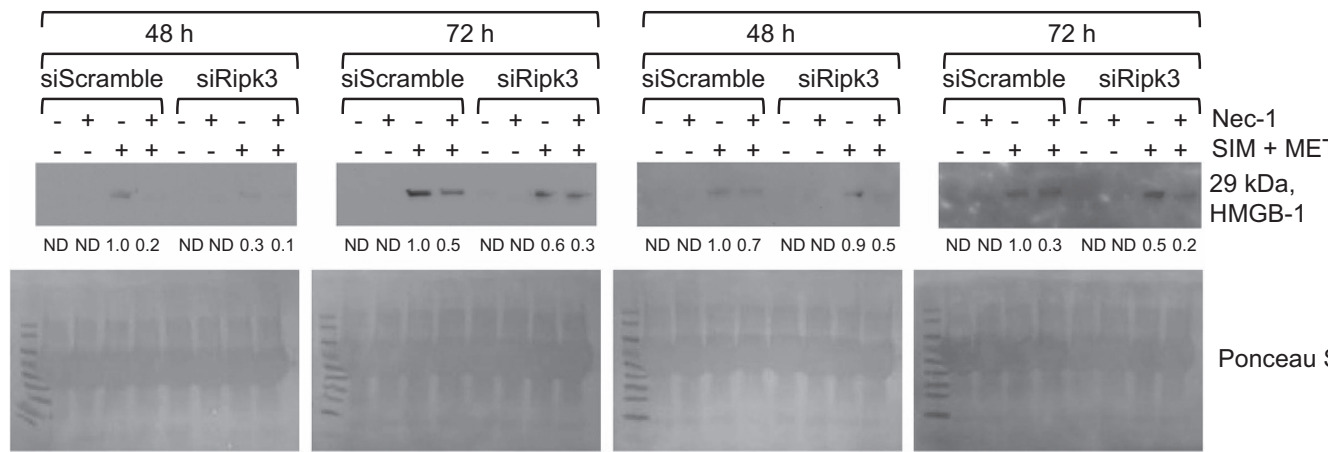

Ponceau S 
C4-2B cells were necrotic even in an untreated state; $12 \%$ of $\mathrm{C} 4-2 \mathrm{~B}$ cells were $\mathrm{PI}(+)$ at $48 \mathrm{~h}$ significantly increasing to $24 \%$ at $96 \mathrm{~h}$, and Ripk1 and Ripk3 expression and necrosome formation also increased with timecourse; this is not surprising, as necrotic cells are often observed in prostate tumors following castration and in metastases. ${ }^{56}$

Cells employ autophagy to maintain cellular metabolism under starvation conditions and to remove damaged organelles under stress conditions to improve survival. ${ }^{52} \mathrm{We}$ demonstrated that $\mathrm{C} 4-2 \mathrm{~B}$ cells upregulate autophagy in an attempt to survive SIM+MET chemotherapy. This was not a failed attempt as, in presence of autophagic inhibitor $C Q$, C4-2B cell viability was significantly reduced. Upregulation of autophagy prevented C4-2B cells from dying more rapidly, but was eventually overcome (no viability difference between SIM+MET \pm CQ-treated cells by $96 \mathrm{~h}$ ). If another drug is used in combination with SIM+MET to block autophagic flux without affecting increased AMPK activity, perhaps targeting ULK1 and ULK2 downstream of AMPK, chemotherapeutic applicability of SIM+MET may be further improved and lead to more pronounced CRPC cell death.

The mitochondrial changes noted in SIM+MET-treated C4-2B cells are interesting and require further investigation. SIM+MET treatment appears to prevent mitochondrial division, as indicated by fewer mitochondria, fewer dividing mitochondria in treated cells, and large mitochondria with what appear to be multiple bodies within the mitochondrial membrane (Figure 5a). SIM+MET treatment may be inhibiting mitochondrial complex I activity, coenzyme Q10 and ATP synthesis, and inducing oxidative stress-induced mitochondrial dysfunction; ${ }^{12,14,39}$ it is also unknown whether these mitochondrial changes are effects of SIM or MET treatment alone or, more likely, a combinatorial effect. Further investigation will also be needed to determine whether mitoptosis is occurring (Figure 5a, white arrows) or whether these areas are cytoplasmic inclusions. Low cellular levels of ATP favor cell death by necrosis, as was observed with SIM+MET treatment in $\mathrm{C} 4-2 \mathrm{~B}$ cells, whereas complete ATP depletion triggers mitoptosis, which is frequently observed in conjunction with necrosis. ${ }^{57}$ Mitochondrial dysfunction and mitoptosis can also lead to mitophagy; although not observed in the single-timepoint TEM images of C4-2B3/B4 at 72-h SIM+MET treatment, autophagic flux upregulation observed at 72 - 96-h combination treatment may be in part due to mitophagy of abnormal mitochondria. The mechanism of how SIM+MET induces these mitochondrial alterations in CRPC cells will be investigated further.

Because normal cells do not possess the same metabolic aberrations as metastatic CRPC cells, SIM+MET treatment had only a minimal effect on normal prostate epithelial cell viability, $\sim 5 \%$ decrease in viability at the top-end of the pharmacological range. ${ }^{10}$ In stark contrast, SIM+MET treatment significantly inhibits metastatic CRPC cell viability and metastatic properties, ameliorates CRPC metabolic aberrations, and induces cell cycle arrest and necrotic cell death in CRPC cells. Although C4-2B cells are resistant to cell death by extrinsic apoptosis, they are not resistant to necrotic cell death, making SIM+MET an excellent novel potential chemotherapeutic option for apoptosis- and chemotherapyresistant metastatic CRPC cells.

\section{Materials and methods}

Cell culture and conditions. C4-2B3 and C4-2B4 cells were a generous gift from Dr. Robert A Sikes, University of Delaware, and were maintained in 10\% FBS (Invitrogen Life Technologies, Grand Island, NY, USA) 1\% penicillin-streptomycin (HyClone, Fisher Scientific, Pittsburgh, PA, USA) RPMI-1640 (HyClone, Fisher Scientific) in a $37-{ }^{\circ} \mathrm{C}$ incubator with an atmosphere of $5 \% \mathrm{CO}_{2}$.

Reagents. SIM and MET (AK Scientific, Union City, CA, USA); RNase A (Fisher Scientific); z-VAD-fmk (BD Biosciences, San Diego, CA, USA); PI, (S)(+)-camptothecin, rapamycin, CQ, and AO (Sigma-Aldrich, St. Louis, MO, USA); necrostatin-1 (R\&D Systems, Richfield, MN, USA). The prodrug simvastatin was activated to simvastatin acid before in vitro use. ${ }^{10}$

Methylene blue assay. Assay was performed as described previously. ${ }^{10}$ Briefly, cells were cultured in 24-well plates; following treatment, cells were washed with PBS, stained with $2 \mathrm{~g} / \mathrm{l}$ methylene blue solution for $1 \mathrm{~h}$, and excess stain removed with $\mathrm{ddH}_{2} \mathrm{O}$. For semi-quantification, bound methylene blue was eluted with $0.1 \mathrm{~N} \mathrm{HCl}$ with shaking, and absorbance measured spectrophotometrically at $\lambda=650 \mathrm{~nm}$ (FLUOstar Omega, BMG Labtech, Ortenburg, Germany).

Microscope images. Following treatment for $24-72 \mathrm{~h}$, images captured at $\times 10$ and $\times 40$ magnification using an Olympus CKX41 microscope and DP12 digital microscope camera (Olympus America, Melville, NY, USA).

Cell cycle analysis by PI flow cytometry. C4-2B cells were serumstarved overnight to synchronize, treated with $4 \mu \mathrm{M}$ SIM and/or $2 \mathrm{mM}$ MET for $24-96 \mathrm{~h}$, trypsinized, washed twice with cold $1 \times$ PBS, and $1 \times 10^{6}$ cells fixed and permeablized with $90 \%$ cold methanol overnight at $-20^{\circ} \mathrm{C}$. Cells were then incubated at $37^{\circ} \mathrm{C}$ with $20 \mu \mathrm{g} / \mathrm{ml}$ RNase A in $1 \times$ PBS for 30 min, stained with $50 \mu \mathrm{g} / \mathrm{ml} \mathrm{PI}$ for $30 \mathrm{~min}$, and analyzed using an Epics XL cytometer (Beckman Coulter, Miami, FL, USA), EXPO32 acquisition software (version 12, Verity Software House Inc., Topsham, ME, USA), and WinList analysis software (version 7, Verity Software House Inc).

Western blot analysis. Total cell lysates of exponentially growing cells were prepared by homogenization using stainless steel beads (Next Advance, Averill

Figure 8 SIM+MET-induced necrosis in C4-2B metastatic CRPC cells is both Ripk1- and Ripk3 dependent. (a) Percentage cell viability (mean \pm S.D.) by the methylene blue assay in non-targeting (siScramble) and Ripk3-targeting (siRipk3) siRNA transfected C4-2B3 and C4-2B4 cells following treatment with $50 \mu \mathrm{M}$ Ripk1 inhibitor necrostatin-1 (Nec-1) or combination $4 \mu \mathrm{M}$ simvastatin (SIM) and $2 \mathrm{mM}$ metformin (MET) $\pm 25-100 \mu \mathrm{M} \mathrm{Nec}-1$ for $72 \mathrm{~h}, n=3$ separate experiments. ${ }^{*} P<0.05,{ }^{* *} P<0.01,{ }^{* \star *} P<0.001, \mathrm{NS}=$ not significant, as determined by ANOVA followed by the Tukey multiple comparison procedure. (b) Treatment of C4-2B3 and C4-2B4 cells with $50 \mu \mathrm{M}$ Nec-1 for $72 \mathrm{~h}$ and siRNA knockdown of Ripk3 expression additively reduces Ripk1-Ripk3 association. Immunoprecipitation of $600 \mu \mathrm{g}$ protein from total cell lysates of non-targeting (siScramble) and Ripk3-targeting (siRipk3) siRNA-transfected C4-2B3 and C4-2B4 cells treated with $50 \mu \mathrm{M} \mathrm{Nec-1}$ and/or combination $4 \mu \mathrm{M}$ SIM and 2 mM MET was conducted with Ripk1 and Ripk3 antibodies followed by western blot with Ripk1, Ripk3, and GAPDH antibodies. No GAPDH was detected in immunoprecipitates (not shown). Forty $\mu \mathrm{g}$ protein from total cell lysates were also immunoblotted as a control (input). Protein expression was quantified by densitometry normalized to GAPDH loading control (mean from two separate experiments). Ripk3 siRNA resulted in $62-64 \%$ knockdown in Ripk3 protein expression at $48 \mathrm{~h}$ and $48-56 \%$ knockdown at $72 \mathrm{~h}$. (c) Western blot analysis of HMGB-1 protein in $40 \mu \mathrm{l}$ conditioned media from non-targeting (siScramble) and Ripk3-targeting (siRipk3) siRNA-transfected C4-2B3 and C4-2B4 cells following treatment with $50 \mu \mathrm{M}$ Nec-1 and/ or combination $4 \mu \mathrm{M} \mathrm{SIM}$ and $2 \mathrm{mM}$ MET for $48-72 \mathrm{~h}$. HMGB-1 protein expression quantified by densitometry (mean from two separate experiments). ND, none detected. Ponceau S stain used to demonstrate equal loading 
Park, NY, USA) as described previously. ${ }^{10}$ Forty $\mu \mathrm{g}$ of protein was denatured at $95^{\circ} \mathrm{C}$, resolved over $4-20 \%$ SDS-PAGE (Bio-Rad, Hercules, CA, USA), and transferred to a nitrocellulose membrane. Following Ponceau $S$ visualization and blocking with 5\% nonfat dry milk TBST, pH 7.4 (USB Molecular Biology Reagents, Affymetrix, Cleveland, $\mathrm{OH}, \mathrm{USA}$ ) for $1 \mathrm{~h}$, the membrane was probed with primary antibody overnight at $4{ }^{\circ} \mathrm{C}$ (Supplementary Table S1), incubated with corresponding HRP-conjugated secondary antibody (Santa Cruz Biotechnology, Santa Cruz, CA, USA), and detected using Pierce ECL reagent (Fisher Scientific). Bands were visualized upon autoradiography film (Denville Scientific, Metuchen, NJ, USA) exposure, quantified using Image $\mathrm{J}$ software ( $\mathrm{NIH}$, Bethesda, MD, USA), and normalized to the loading control. Total cell lysates for autophagic analysis were prepared with $2 \%$ Triton-X 100 lysis buffer, in order to properly extract hydrophobic LC3B-II, ${ }^{32}$ and resolved over a $12 \%$ SDS-PAGE. For western blot analysis of media protein, $40 \mu \mathrm{l}$ conditioned media per sample was resolved and transferred as above, and blots were stained with Ponceau $S$ to demonstrate equal loading and photographed.

PI/AV flow cytometric analysis. Assay performed according to the manufacturer's instructions (Annexin V-FITC Apoptosis Detection Kit, Phoenix Flow Systems, San Diego, CA, USA). Briefly, C4-2B cells were serum-starved overnight, treated with $4 \mu \mathrm{M}$ SIM and/or $2 \mathrm{mM}$ MET for $48-96 \mathrm{~h}$, trypsinized, washed with $1 \mathrm{x}$ $\mathrm{PBS}$, and $1 \times 10^{6}$ cells incubated and stained with $\mathrm{AV}$ and $\mathrm{PI}$, and analyzed using an Epics XL cytometer (Beckman Coulter), EXPO32 acquisition software, and WinList analysis software (version 7, Verity Software House Inc.) alongside control samples.

AO staining for AVOs detection by flow cytometry. Following indicated treatment, $\mathrm{C} 4-2 \mathrm{~B} 3$ and $\mathrm{C} 4-2 \mathrm{~B} 4$ cells were stained with $1 \mu \mathrm{g} / \mathrm{ml} \mathrm{AO}$ in complete media for $15 \mathrm{~min}$, then washed with $1 \times$ PBS, trypsinized, resuspended at $1 \times 10^{6}$ cells per ml cold $1 \times$ PBS, and analyzed by flow cytometry. For quantization of percentage of AVO-positive cells, red ( $620 \mathrm{BP}, \mathrm{FL} 3$ channel, where BP $=$ band pass) and green (525 BP, FL1 channel) fluorescence emissions from $3 \times 10^{4}$ cells from samples and control specimens illuminated with blue $(488 \mathrm{~nm})$ excitation light was analyzed using an Epics XL cytometer (Beckman Coulter), EXPO32 acquisition software, and WinList analysis software (version 7, Verity Software House Inc.), according to published protocol. ${ }^{36,58}$

Transmission electron microscopic analysis. $\mathrm{C} 4-2 \mathrm{~B} 3$ and $\mathrm{C} 4-2 \mathrm{~B} 4$ cells $\left(1 \times 10^{5}\right)$ were seeded onto $3.0 \mathrm{mg} / \mathrm{ml}$ Matrigel (BD Biosciences)-coated sterilized Aclar Embedding Film (Electron Microscopy Sciences, Hatfield, PA, USA) lining the wells of $35-\mathrm{mm}$ culture plates, then treated with combination $4 \mu \mathrm{M}$ SIM and $2 \mathrm{mM} \mathrm{MET}$ or untreated for $72 \mathrm{~h}$. Cells were then fixed and processed for TEM according to the published protocol ${ }^{59}$ and analyzed using a FEI T12 Tecnai Spirit electron microscope (FEI, Hillsboro, OR, USA).

Immunoprecipitation. Ripk1 and Ripk3 were immunoprecipitated from $600 \mu \mathrm{g}$ pre-cleared whole-cell lysate as per the manufacturer's protocol using $1.0 \mu \mathrm{g}$ primary antibody and $20 \mu \mathrm{l}$ Protein G-Agarose (Roche Diagnostics, Indianapolis, IN, USA) and Protein A/G PLUS-Agarose (Santa Cruz Biotechnology) conjugate suspension, respectively. Immunoprecipitates were washed four times, reduced, boiled, and resolved by SDS-PAGE as described above. Immunoprecipitate blots were probed to confirm absence of GAPDH to ensure proper separation and pull down.

Quantization of conditioned media protein. Protein concentration $(\mu \mathrm{g} / \mu \mathrm{l})$ assessed in $5 \mu \mathrm{l}$ conditioned media (performed in triplicate) using the Lowry protein assay kit (Bio-Rad).

RNA interference of Ripk3 expression. Cells were transfected with 40 pmol either SMARTpool ON-TARGETplus Ripk3 siRNA or ON-TARGETplus nontargeting siRNA (Thermo Scientific Dharmacon) using X-tremeGENE 9 DNA Transfection Reagent (Roche Diagnostics) as per the manufacturer's protocol.

Statistics. Quantitative values represented as mean \pm S.D. of at least three independent experiments. Significance was determined by a two-tailed, unpaired Student's $t$-test or ANOVA, followed by the Tukey multiple comparison procedure (SAS 9.3, version 9.3, SAS Institute Inc., Cary, NC, USA). Comparisons resulting in $P<0.05$ considered statistically significant and identified with an asterisk $\left({ }^{*}\right)$, $P<0.01$ identified with double asterisk $\left(^{* *}\right)$, and $P<0.001$ identified with triple asterisk (***).

\section{Conflict of Interest}

The authors declare no conflict of interest.

Acknowledgements. We thank Dr. Robert A Sikes of the Center for Translational Cancer Research, University of Delaware (Newark, DE) for the gift of the C4-2B cell lines. We thank Drs Laura Nagy, Jonathan Sears, George Hoppe of the Cleveland Clinic (Cleveland, $\mathrm{OH}$ ), and George Dubyak and Alvin H Schmaier of Case Western Reserve University (Cleveland, $\mathrm{OH}$ ) for reagents necessary for completion of this work. We thank the Case Comprehensive Cancer Center for use of the Cytometry and Imaging Microscopy Core. MAB is supported by the $\mathrm{NIH}$ 5T32DK007319 Ruth L Kirschstein Pre-Doctoral Fellowship through the Metabolism Training Program. This work was supported by NIH R01CA10852 awarded to SG, NIH R01CA127264 awarded to AA, and Urology Vision Research Funds.

1. American Cancer Society. Cancer Facts \& Figures 2014. American Cancer Society: Atlanta, GA, USA, 2014

2. Cookson MS, Roth BJ, Dahm P, Engstrom C, Freedland SJ, Hussain M et al. Castrationresistant prostate cancer: AUA Guideline. J Urol 2013; 190: 429-438.

3. Loblaw DA, Walker-Dilks C, Winquist E, Hotte SJ. Genitourinary Cancer Disease Site Group of Cancer Care Ontario's Program in Evidence-Based Care, Systemic therapy in men with metastatic castration-resistant prostate cancer: a systematic review. Clin Oncol ( $R$ Coll Radiol) 2013; 25: 406-430.

4. Tannock IF, de Wit R, Berry WR, Horti J, Pluzanska A, Chi KN et al. Docetaxel plus prednisone or mitoxantrone plus prednisone for advanced prostate cancer. N Engl J Med 2004; 351: 1502-1512.

5. Vander Heiden MG, Cantley LC, Thompson CB. Understanding the Warburg effect: the metabolic requirements of cell proliferation. Science 2009; 324: 1029-1033.

6. Faubert B, Boily G, Izreig S, Griss T, Samborska B, Dong Z et al. AMPK is a negative regulator of the Warburg effect and suppresses tumor growth in vivo. Cell Metab 2013; 17: 113-124.

7. Kreisberg Jl, Malik SN, Prihoda TJ, Bedolla RG, Troyer DA, Kreisberg S et al. Phosphorylation of Akt (Ser473) is an excellent predictor of poor clinical outcome in prostate cancer. Cancer Res 2004; 64: 5232-5236.

8. Mimeault M, Johansson SL, Batra SK. Pathobiological implications of the expression of EGFR, pAkt, NF-KB and MIC-1 in prostate cancer stem cells and their progenies. PLoS One 2012; 7: e31919.

9. Thysell E, Surowiec I, Hörnberg E, Crnalic S, Widmark A, Johansson Al et al. Metabolomic characterization of human prostate cancer bone metastases reveals increased levels of cholesterol. PLoS One 2010; 5: e14175

10. Babcook MA, Shukla S, Fu P, Vazquez EJ, Puchowicz MA, Molter JP et al. Synergistic Simvastatin and Metformin Combination Chemotherapy for Osseous Metastatic CastrationResistant Prostate Cancer. Mol Cancer Ther 2014; 13: 2288-2302.

11. Lennernäs $H$, Fager $G$. Pharmacodynamics and pharmacokinetics of the HMG-CoA reductase inhibitors. Similarities and differences. Clin Pharmacokinet. 1997; 32: 403-425.

12. Stephenne X, Foretz M, Taleux N, van der Zon GC, Sokal E, Hue L et al. Metformin activates AMP-activated protein kinase in primary human hepatocytes by decreasing cellular energy status. Diabetologia 2011; 54: 3101-3110.

13. Park YH, Seo SY, Lee E, Ku JH, Kim HH, Kwak C. Simvastatin induces apoptosis in castrate resistant prostate cancer cells by deregulating nuclear factor-кB pathway. J Urol 2013; 189 : $1547-1552$.

14. Costa RA, Fernandes MP, de Souza-Pinto NC, Vercesi AE. Protective effects of I-carnitine and piracetam against mitochondrial permeability transition and PC3 cell necrosis induced by simvastatin. Eur J Pharmacol 2013; 701: 82-86.

15. Araki M, Motojima K. Hydrophobic statins induce autophagy in cultured human rhabdomyosarcoma cells. Biochem Biophys Res Commun 2008; 367: 462-467.

16. Akinyeke T, Matsumura S, Wang X, Wu Y, Schalfer ED, Saxena A et al. Metformin targets C-MYC oncogene to prevent prostate cancer. Carcinogenesis 2013; 34: 2823-2832.

17. Takahashi A, Kimura F, Yamanaka A, Takebayashi A, Kita N, Takahashi K et al. Metformin impairs growth of endometrial cancer cells via cell cycle arrest and concomitant autophagy and apoptosis. Cancer Cell Int 2014; 14: 53.

18. Bonini MG, Gantner BN. The multifaceted activities of AMPK in tumor progression-why the "one size fits all" definition does not fit at all? IUBMB Life 2013; 65: 889-896.

19. Lu H, Li X, Luo Z, Liu J, Fan Z. Cetuximab reverses the Warburg effect by inhibiting HIF-1regulated LDH-A. Mol Cancer Ther 2013; 12: 2187-2199.

20. Hoque $A$, Chen $H, X u X C$. Statin induces apoptosis and cell growth arrest in prostate cancer cells. Cancer Epidemiol Biomarkers Prev 2008; 17: 88-94.

21. Goc A, Kochuparambil ST, Al-Husein B, Al-Azayzih A, Mohammad S, Somanath PR. Simultaneous modulation of the intrinsic and extrinsic pathways by simvastatin in mediating prostate cancer cell apoptosis. BMC Cancer 2012; 12: 409.

22. Vermeulen K, Van Bockstaele DR, Berneman ZN. Apoptosis: mechanisms and relevance in cancer. Ann Hematol 2005; 84: 627-639.

23. Wlodkowic D, Skommer J, Darzynkiewicz Z. Cytometry of apoptosis. Historical perspective and new advances. Exp Oncol 2012; 34: 255-262. 
24. Elumalai P, Gunadharini DN, Senthilkumar K, Banudevi S, Arunkumar R, Benson CS et al. Induction of apoptosis in human breast cancer cells by nimbolide through extrinsic and intrinsic pathway. Toxicol Lett 2012; 215: 131-142.

25. Demchenko AP. The change of cellular membranes on apoptosis: fluorescence detection. Exp Oncol 2012; 34: 263-268.

26. Yedjou CG, Saeed MA, Hossain MA, Dorsey W, Yu H, Tchounwou PB. Basic apoptotic and necrotic cell death in human liver carcinoma (HepG2) cells induced by synthetic azamacrocycle. Environ Toxicol 2014; 29: 605-611.

27. Krysko DV, Vanden Berghe T, D'Herde K, Vandenabeele P. Apoptosis and necrosis: detection, discrimination and phagocytosis. Methods 2008; 44: 205-221.

28. Koka PS, Mondal D, Schultz M, Abdel-Mageed AB, Agrawal KC. Studies on molecular mechanisms of growth inhibitory effects of thymoquinone against prostate cancer cells: role of reactive oxygen species. Exp Biol Med (Maywood) 2010; 235: 751-760.

29. Nikoletopoulou V, Markaki M, Palikaras K, Tavernarakis N. Crosstalk between apoptosis, necrosis and autophagy. Biochim Biophys Acta 2013; 1833: 3448-3459.

30. Zhang J, Yang Z, Xie L, Xu L, Xu D, Liu X. Statins, autophagy and cancer metastasis. Int J Biochem Cell Biol 2013; 45: 745-752.

31. Hansen TE, Johansen T. Following autophagy step by step. BMC Biol 2011; 9: 39

32. Tanida I, Ueno T, Kominami E. LC3 and Autophagy. Methods Mol Biol 2008; 445: 77-88.

33. Mizushima N, Yoshimori T. How to interpret LC3 immunoblotting. Autophagy 2007; 3 . 542-545

34. Klionsky DJ, Abdalla FC, Abeliovich H, Abraham RT, Acevedo-Arozena A, Adeli K et al. Guidelines for the use and interpretation of assays for monitoring autophagy. Autophagy 2012; 8: 445-544.

35. Bjørkøy G, Lamark T, Pankiv S, Øvervatn A, Brech A, Johansen T. Monitoring autophagic degradation of p62/SQSTM1. Methods Enzymol 2009; 452: 181-197.

36. Singh K, Matsuyama S, Drazba JA, Almasan A. Autophagy-dependent senescence in response to DNA damage and chronic apoptotic stress. Autophagy 2012; 8: 236-251.

37. Periyasamy-Thandavan S, Jiang M, Schoenlein P, Dong Z. Autophagy: molecular machinery, regulation, and implications for renal pathophysiology. Am J Physiol Renal Physiol 2009; 297: F244-F256.

38. He W, Wang Q, Srinivasan B, Xu J, Padilla MT, Li Z et al. A JNK-mediated autophagy pathway that triggers C-IAP degradation and necroptosis for anticancer chemotherapy. Oncogene 2014; 33: 3004-3013.

39. Oliveira KA, Zecchin KG, Alberici LC, Castilho RF, Vercesi AE. Simvastatin inducing PC3 prostate cancer cell necrosis mediated by calcineurin and mitochondrial dysfunction. J Bioenerg Biomembr 2008; 40: 307-314.

40. Cho YS, Challa S, Moquin D, Genga R, Ray TD, Guildford M et al. Phosphorylation-driven assembly of the RIP1-RIP3 complex regulates programmed necrosis and virus-induced inflammation. Cell 2009; 137: 1112-1123.

41. Chan FK, Baehrecke EH. RIP3 finds partners in crime. Cell 2012; 148: 17-18.

42. Thapa RJ, Nogusa S, Chen P, Maki JL, Lerro A, Andrake M et al. Interferon-induced RIP1/RIP3-mediated necrosis requires PKR and is licensed by FADD and caspases. Proc Natl Acad Sci USA 2013; 110: E3109-E3118.

43. Fu Z, Deng B, Liao Y, Shan L, Yin F, Wang Z et al. The anti-tumor effect of shikonin on osteosarcoma by inducing RIP1 and RIP3 dependent necroptosis. BMC Cancer 2013; 13: 580 .

44. Whilding LM, Archibald KM, Kulbe H, Balkwill FR, Öberg D, McNeish IA. Vaccinia virus induces programmed necrosis in ovarian cancer cells. Mol Ther 2013; 21: 2074-2086.
45. Kaiser WJ, Sridharan H, Huang C, Mandal P, Upton JW, Gough PJ et al. Toll-like receptor 3-mediated necrosis via TRIF, RIP3, and MLKL. J Biol Chem 2013; 288: 31268-31279.

46. Seya T, Shime H, Takaki H, Azuma M, Oshiumi H, Matsumoto M. TLR3/TICAM-1 signaling in tumor cell RIP3-dependent necroptosis. Oncoimmunology 2012; 1: 917-923.

47. Oerlemans MI, Liu J, Arslan F, den Ouden K, van Middelaar BJ, Doevendans PA et al Inhibition of RIP1-dependent necrosis prevents adverse cardiac remodeling after myocardial ischemia-reperfusion in vivo. Basic Res Cardiol 2012; 107: 270.

48. Moriwaki K, Chan FK. Necrosis-dependent and independent signaling of the RIP kinases in inflammation. Cytokine Growth Factor Rev 2014; 25: 167-174.

49. Xiang X, Saha AK, Wen R, Ruderman NB, Luo Z. AMP-activated protein kinase activators can inhibit the growth of prostate cancer cells by multiple mechanisms. Biochem Biophys Res Commun 2004; 321: 161-167.

50. Altman BJ, Rathmell JC. Metabolic stress in autophagy and cell death pathways. Cold Spring Harb Perspect Biol 2012; 4: a008763.

51. Wang D, Montgomery RB, Schmidt LJ, Mostaghel EA, Huang H, Nelson PS et al. Reduced tumor necrosis factor receptor-associated death domain expression is associated with prostate cancer progression. Cancer Res. 2009; 69: 9448-9456.

52. Wilson C, Wilson T, Johnston PG, Longley DB, Waugh DJ. Interleukin-8 signaling attenuates TRAIL- and chemotherapy-induced apoptosis through transcriptional regulation of C-FLIP in prostate cancer cells. Mol Cancer Ther 2008; 7: 2649-2661.

53. Lawrence CP, Chow SC. FADD deficiency sensitises Jurkat T cells to TNF-alpha-dependent necrosis during activation-induced cell death. FEBS Lett 2005; 579: 6465-6472.

54. Darzynkiewicz Z, Juan G. DNA content measurement for DNA ploidy and cell cycle analysis. Curr Protoc Cytom 2001; Chapter 7: Unit 7.5.

55. Riccardi C, Nicoletti I. Analysis of apoptosis by propidium iodide staining and flow cytometry. Nat Protoc 2006; 1: 1458-1461.

56. Zhang KX, Firus J, Prieur B, Jia W, Rennie PS. To die or to survive, a fatal question for the destiny of prostate cancer cells after androgen deprivation therapy. Cancers (Basel) 2011; 3 : 1498-1512.

57. Skulachev VP. Bioenergetic aspects of apoptosis, necrosis and mitoptosis. Apoptosis 2006; 11: $473-485$

58. Jiang H, White EJ, Conrad C, Gomez-Manzano C, Fueyo J. Autophagy pathways in glioblastoma. Methods Enzymol 2009; 453: 273-286.

59. Fujioka H, Tandler B, Consolo MC, Karnik P. Division of mitochondria in cultured human fibroblasts. Microsc Res Tech 2013; 76: 1213-1216.

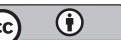

Cell Death and Disease is an open-access journal published by Nature Publishing Group. This work is licensed under a Creative Commons Attribution 4.0 International Licence. The images or other third party material in this article are included in the article's Creative Commons licence, unless indicated otherwise in the credit line; if the material is not included under the Creative Commons licence, users will need to obtain permission from the licence holder to reproduce the material. To view a copy of this licence, visit http://creativecommons.org/licenses/by/4.0 